\title{
A Comprehensive Performance Assessment Study of Pilot-Scale Pd and Pd/Alloy Membranes under Extended Coal-Derived Syngas Atmosphere Testing
}

\author{
Ivan P. Mardilovich ${ }^{\mathrm{a}}$, Bernardo Castro-Dominguez ${ }^{\mathrm{a}}$, Nikolaos K. Kazantzis ${ }^{\mathrm{a}}$, Tony Wu ${ }^{\mathrm{b}}$, Yi Hua Ma ${ }^{\mathrm{a}, 1}$ \\ ${ }^{a}$ Center of Inorganic Membrane Studies (CIMS), Department of Chemical Engineering, Worcester \\ Polytechnic Institute, 100 Institute Road, 01609 Worcester, MA, USA. \\ ${ }^{b}$ National Carbon Capture Canter, Southern Company, P.O. Box 1069 Wilsonville, Alabama 35186
}

United States.

\begin{abstract}
The present study encompasses the results of a comprehensive performance assessment of different pilot-scale Pd/Alloy composite asymmetric membranes under long-term coal-derived syngas atmosphere testing. The membranes were developed and tested first at the CIMS-WPI laboratory under pure $\mathrm{H}_{2}$ and later at $\mathrm{NCCC}$ under a mixture of $\mathrm{N}_{2} / \mathrm{H}_{2}$ and $\mathrm{H}_{2}$ enriched syngas coming from a TRIG $^{\mathrm{TM}}$ gasification system. Thirteen membranes were examined for $4275 \mathrm{~h}$ and classified in four types: $\mathrm{Pd}, \mathrm{Pd} / \mathrm{Au}, \mathrm{Pd} / \mathrm{Pt}$ and $\mathrm{Pd} / \mathrm{Au} / \mathrm{Pt}$ membranes. Their respective $\mathrm{H}_{2}$ permeance and purity profiles, permeance difference under pure hydrogen and syngas conditions as well as stability of operation were assessed. The membranes showed good stability in syngas although exhibiting an initial drop in permeance when compared to that under pure hydrogen. Pure Pd membranes displayed the highest permeability, but showed pinholes after being exposed to syngas. $\mathrm{Pd} / \mathrm{Pt}$ membranes showed a reduced permeance drop under syngas conditions, indicating sulfur resistance properties. Furthermore, $\mathrm{Pd} / \mathrm{Au} / \mathrm{Pt}$ membranes, presented for the first time in the literature, displayed stable permeance and purity profile. The inhibition of the initial permeance drop and the long-term operation of these ternary membranes were demonstrated. Finally, $\mathrm{Pd} / \mathrm{Au}$ membranes were shown to display the most stable permeance and purity characteristics. In this case, the initial permeance drop was significantly reduced, exhibiting the lowest decline amongst all cases considered. It is hypothesized that Au may act as a patch paste blocking defects on the Pd layer.
\end{abstract}

\section{Keywords}

${ }^{1}$ Corresponding author: Telephone: +1-508-831-5398, Email: yhma.wpi.edu 
Pilot-scale; Composite Asymmetric Pd/Alloy Membranes; Hydrogen Separation, Coal-derived Syngas; Long-term Stability

\section{Introduction}

Hydrogen, a major component of the petrochemical and chemical industry, is commonly used for the hydrogenation, hydroalkylation, hydrodenitrogenation and hydrodesulfurization of fossil fuels. In addition, its utilization has become significant in the energy field, where the search of an alternative, clean and stable energy carrier and storage medium is imperative. Hydrogen is currently produced mainly by methane steam reforming (MSR) and water gas shift (WGS) reaction. These processes yield hydrogen mixed with byproducts such as $\mathrm{CO}, \mathrm{CO}_{2}$ and $\mathrm{CH}_{4}$, which make the purification of hydrogen essential.

According to Koros et al. [1] the two main challenges for the large-scale application of a gas separation technology are: the need of high permselectivity and productivity as well as maintaining these properties in the presence of aggressive feeds; all of these under economic competitiveness conditions. Compared with pressure swing adsorption (PSA) and cryogenic distillation, the use of membranes reduces the costs of hydrogen production [2]. Membrane technology also requires fewer moving parts and has compact modules compared to other technologies [3]. Therefore, membranes are strong candidates to perform the purification of $\mathrm{H}_{2}$. Specifically, palladium membranes are ideal due to their capability of producing ultrapure $\mathrm{H}_{2}$ with large fluxes and high recovery rates. Additionally, Pd membranes can be used for process intensification purposes such as in catalytic membrane reactors (CMRs) [4,5].

Before considering any viable expansion possibilities of the range of industrial applications of Pd-based membranes, it is necessary to conduct comprehensive large-scale studies (20-40 $\mathrm{Nm}^{3} \mathrm{~h}^{-1}$ ) under actual industrial conditions [6]. Indeed, only a few studies have dealt with such an assessment in a noncontrolled environment. For instance, Defalco et al. [7] and Shirasaki et al. [8] used a premixed syngas formed by a previously "contaminant-treated" and desulfurized industrial cylinder gas. Furthermore, at the Center for Inorganic Membrane Studies at Worcester Polytechnic Institute (CIMS-WPI), our group [9] studied the behavior of pilot-scale Pd membranes in a catalytic membrane reactor for the water gas shift (WGS) reaction. Industrial cylinder gas was used to feed $\mathrm{CO}, \mathrm{CO}_{2}, \mathrm{H}_{2}$ and $\mathrm{H}_{2} \mathrm{O}$ into the reactor. Even though these represent the major components in a WGS reaction system, impurities and intermediates might affect the performance of the membrane. Therefore, more realistic test settings are required to evaluate the performance of Pd membranes. Indeed, actual coal-derived syngas contains contaminants such as sulfuric components which, can cause the membrane to fail even when found at small traces [6]. Some of the contaminants present in actual coal-derived syngas include: $\mathrm{H}_{2} \mathrm{~S}, \mathrm{COS}, \mathrm{NH}_{3}$, $\mathrm{HCN}, \mathrm{C}_{2}$ hydrocarbons, poly aromatic hydrocarbons, halides, heavy metals, tellurides, alkalis metals, phosphorous and others [6]. To the best of our knowledge, detailed comprehensive studies on the effect of 
these contaminants on the performance of Pd membranes under industrial conditions have not yet been reported in the pertinent literature.

On the other hand, membrane poisoning is an issue that has been intensively studied. To reduce poisoning, different Pd-rich membranes such as $\mathrm{Pd} / \mathrm{Cu}$ [10], $\mathrm{Pd} / \mathrm{Ag}[11]$ and $\mathrm{Pd} / \mathrm{Au}[12,13,14]$ have been tested. In particular, at the CIMS-WPI, we studied the performance of pilot scale Pd/Au membranes under actual coal derived syngas conditions $[6,14]$. It was found that the $\mathrm{H}_{2}$ permeance dropped initially when syngas was fed into the membrane module. However, the stability of the membrane remained constant for $200 \mathrm{~h}$. The $\mathrm{Pd} / \mathrm{Au}$ membrane was capable of achieving a $\mathrm{H}_{2}$ purity of $98.89 \%$ during the entire test. Later [14], it was shown that the permeance of the poisoned $\mathrm{Pd} / \mathrm{Au}$ membranes could be recovered to their original value after exposure to pure $\mathrm{H}_{2}$ at $450^{\circ} \mathrm{C}$. Motivated by the above preliminary research efforts, the development of a more comprehensive performance analysis framework allowing the derivation of new results to complement and refine the ones of our previous studies represents a natural subsequent step towards the goal of enhancing our understanding of the behavior of pilot-scale $\mathrm{Pd}$ and $\mathrm{Pd} / \mathrm{Alloy}$ membranes under long-term coal-derived syngas atmosphere testing. It should be pointed out that membranes previously reported by our group along with new membranes are included in the present study to further strengthen statistical inference and reliability of the performance assessment results derived within the proposed framework. All membranes were classified in four groups: pure $\mathrm{Pd}, \mathrm{Pd} / \mathrm{Au}$, $\mathrm{Pd} / \mathrm{Pt}$ and $\mathrm{Pd} / \mathrm{Au} / \mathrm{Pt}$ membranes in order to understand the effect of the alloy on the properties of the membranes. The investigation includes tests under pure $\mathrm{H}_{2}, \mathrm{H}_{2} / \mathrm{N}_{2}$ mixed gas, and actual coal derived syngas. The $\mathrm{H}_{2}$ permeance, $\mathrm{H}_{2}$ purity, stability characteristics of each membrane as well as the effects of $\mathrm{CO}, \mathrm{CO}_{2}$ and $\mathrm{H}_{2}$ on membrane performance are comprehensively examined, comparatively assessed and discussed.

\section{Materials and Methods}

\subsection{Membrane Preparation}

Composite asymmetric membranes were synthesized, as previously described [6], on porous stainless steel (PSS) tubular supports 316L [15] from MOTT Metallurgical with an outer diameter of $0.025 \mathrm{~m}$ and a length of $0.254 \mathrm{~m}$. The total porous surface area of the membrane was $200 \mathrm{~cm}^{2}$. One end was welded to a $0.076 \mathrm{~m}$ long $316 \mathrm{~L}$ nonporous tube capped at one end and to a $0.356 \mathrm{~m}$ long nonporous tube on the other end.

The supports were cleaned with acetone in an ultrasonic bath. The synthesis of the cleaned supports began by oxidizing the support at $600^{\circ} \mathrm{C}$ for $12 \mathrm{~h}$ in air [16]. Activated $\mathrm{Al}_{2} \mathrm{O}_{3}$ particles were used to grade the previously oxidized supports and were cemented with $\operatorname{Pd}[17,18]$. The surface of the membranes were then activated with $\mathrm{SnCl}_{2}-\mathrm{PdCl}_{2}$ and then electroless plating of $\mathrm{Pd}$ was used to form a dense layer of pure 
Pd over the graded supports [19,20,21]. Gold and/or platinum were deposited on the surface of the dense Pd layer by the standard electro deposition method followed by alloying in situ $[5,22,23]$. The thickness of the membranes was estimated by gravimetric methods. Different $\mathrm{Pd}$ and $\mathrm{Pd}$ /Alloy membrane thicknesses were used in order to conduct a comprehensive analysis of each alloy. It should be pointed out that these membranes were designed to produce $\mathrm{H}_{2}$ with purity equal or higher than $99 \%$ and a permeance of $15 \mathrm{Nm}^{3} \mathrm{~m}^{-2} \mathrm{~h}^{-1} \mathrm{bar}^{-0.5}$ under syngas conditions.

Table 1 shows the summary of the principal characteristics of all the composite Pd and Pd/alloy membranes synthesized at the CIMS-WPI and the nomenclature used in this study. Thirteen Pd and $\mathrm{Pd} /$ alloy membranes were tested first at WPI under pure hydrogen for about 100 hours at $450^{\circ} \mathrm{C}$ and afterwards were sent to the National Carbon Capture Center (NCCC) in Wilsonville, Al. to be tested under $\mathrm{H}_{2} / \mathrm{N}_{2}$ mixed gas and syngas conditions at $450^{\circ} \mathrm{C}$ and $12.6 \mathrm{~atm}$. The total effective testing time for all thirteen membranes was $4275 \mathrm{~h}$. Notice that testing results of membranes labelled with an asterisk (*) have been previously reported; nevertheless, these results are retained and used in the present study to extend the statistical range and strengthen its reliability. Two membranes, M- $02^{* * *}$ and M- $06^{* * *}$, were tested in our laboratory under a controlled mixture of $\mathrm{CO}, \mathrm{CO}_{2}, \mathrm{H}_{2} \mathrm{O}$ and $\mathrm{H}_{2}$. Moreover, temperatures ranging between $420-440^{\circ} \mathrm{C}$ and a maximum pressure of 20 bar were used in this work. Notice also that these membranes were used for a catalytic membrane reactor test on a pilot scale [9] in order to better understand and assess the effect of these major syngas components on the membrane under consideration.

Table 1. Summary of the composite Pd and Pd/alloy membranes

\begin{tabular}{|c|c|c|c|}
\hline $\begin{array}{c}\text { Membrane } \\
\text { Nomenclature }\end{array}$ & $\begin{array}{c}\text { Composition and thickness, } \\
\mu \mathrm{m}\end{array}$ & $\begin{array}{l}\text { Testing time, } \\
\mathbf{h}\end{array}$ & Test Setting \\
\hline M-04b & $14(\mathrm{Pd})+0.9(\mathrm{Au})$ & 250 & \multirow{13}{*}{$\begin{array}{c}\text { Industrial } \\
\text { coal derived } \\
\text { syngas and } \\
\mathrm{H}_{2} \text { and } \mathrm{N}_{2} \\
\text { mixture }\end{array}$} \\
\hline M-08 & $8.5(\mathrm{Pd})+0.33(\mathrm{Au})+0.1(\mathrm{Pt})$ & 650 & \\
\hline M-09 & $8.5(\mathrm{Pd})+0.35(\mathrm{Au})+0.06(\mathrm{Pt})$ & 175 & \\
\hline M-10 & $9.6(\mathrm{Pd})$ & 225 & \\
\hline M-11 & $5(\mathrm{Pd})+0.8(\mathrm{Au})+0.9(\mathrm{Pd})$ & 350 & \\
\hline M-12 & $4(\mathrm{Pd})+0.5(\mathrm{Pt})+0.9(\mathrm{Pd})$ & 350 & \\
\hline M-13 & $4.8(\mathrm{Pd})+0.45(\mathrm{Pt})$ & 150 & \\
\hline M-14 & $10.3(\mathrm{Pd})+0.3(\mathrm{Au})+0.09(\mathrm{Pt})$ & 725 & \\
\hline $\mathrm{M}-01^{*}$ & $8.2(\mathrm{Pd})+0.16(\mathrm{Au})$ & 225 & \\
\hline $\mathrm{M}-03^{*}$ & $10(\mathrm{Pd})+0.2(\mathrm{Au})$ & 275 & \\
\hline $\mathrm{M}-03 \mathrm{~b}^{* *}$ & $9.6(\mathrm{Pd})$ & 175 & \\
\hline M-04* & $13.1(\mathrm{Pd})$ & 250 & \\
\hline $\mathrm{M}-07^{* *}$ & $8.7(\mathrm{Pd})+0.5(\mathrm{Au})$ & 475 & \\
\hline $\mathrm{M}-02^{* * *}$ & $7.4(\mathrm{Pd})$ & 450 & \multirow{2}{*}{$\begin{array}{c}\text { Mixture of } \\
\mathrm{CO}, \mathrm{CO}_{2}, \\
\mathrm{H}_{2} \mathrm{O} \text { and } \mathrm{H}_{2}\end{array}$} \\
\hline M-06 & $8.3(\mathrm{Pd})$ & 390 & \\
\hline
\end{tabular}

Described in our previous works: " $[6],{ }^{3 * * *}[9]$ and ${ }^{* * *}[14]$ 


\subsection{Coal-derived Syngas and Membrane Testing}

The details of the skid used at WPI were previously described [6,14]. The syngas produced at NCCC comes from an air blown transport integrated gasification (TRIG ${ }^{\mathrm{TM}}$ ) system fed with powder river basin (PRB) coal. The syngas from the gasifier was cooled down to $400^{\circ} \mathrm{C}$ and sent to a particle control device (PCD) where the particulates were reduced to $0.1 \mathrm{ppmv}$ [24]. Following the removal of particles, the syngas was sent to a WGS shift reactor to reduce the $\mathrm{CO}$ content to $<1 \%$ followed by a $\mathrm{ZnO}$ bed for sulfur removal and then a COS hydrolyser. $\mathrm{A}_{2} \mathrm{~S}$ reduction of $<1 \mathrm{ppm}$ was achieved with undetectable COS based on GC. The syngas used for testing was mixed with industrial $\mathrm{H}_{2}$ for enrichment up to 30$40 \%$ and to increase the driving force for permeation. Afterwards, the enriched syngas passed through a second $\mathrm{ZnO}$ bed. The average syngas feed composition was: $\mathrm{H}_{2}: 33 \%, \mathrm{~N}_{2}: 46 \%, \mathrm{CO}<1 \%, \mathrm{CO}_{2}: 12 \%$, $\mathrm{H}_{2} \mathrm{O}$ : balance. For a more detailed description of the syngas composition and preliminary clean up, the reader is referred to CIMS-WPI's previous work [6]. Finally, it should be pointed out that the hydrogen permeate was measured with a rotameter and its composition by a GC (model Simens Maxum II, columns: HysepN and HA-MS for $\mathrm{H}_{2}, \mathrm{~N}_{2}, \mathrm{CO}$, and $\mathrm{CH}_{4}$; HysepN and HysepQ for $\mathrm{CO}_{2}$ and $\mathrm{H}_{2} \mathrm{~S}$; detector was a TCD).

\section{Results}

\subsection{Group 1. Pure Pd Membranes}

Group 1 is comprised of pure Pd-based membranes. The characteristics of these membranes were used as the standard-basis in our comparative assessment of the performance of the Pd/Alloy membranes. Five Pd membranes were used for this study with different Pd thicknesses ranging from 7.4-13.1 $\mu \mathrm{m}$ (Table 2).

Table 2. Composition of the pure Pd membranes

\begin{tabular}{|c|c|}
\hline Membrane Nomenclature & Composition / $\boldsymbol{\mu m}$ \\
\hline${\mathrm{M}-02^{* * *}}^{* *}$ & $7.4(\mathrm{Pd})$ \\
\hline $\mathrm{M}^{* 03 \mathrm{~b}^{* *}}$ & $9.6(\mathrm{Pd})$ \\
\hline $\mathrm{M}-04^{*}$ & $13.1(\mathrm{Pd})$ \\
\hline $\mathrm{M}-06^{* * *}$ & $8.3(\mathrm{Pd})$ \\
\hline $\mathrm{M}-10$ & $9.6(\mathrm{Pd})$ \\
\hline
\end{tabular}

The $\mathrm{H}_{2}$ permeance of M- $04^{*}$ and M-10 was tested initially under pure $\mathrm{H}_{2}$ at WPI and later under $\mathrm{H}_{2} / \mathrm{N}_{2}$ gas mixture and syngas at NCCC. The respective profiles are shown in Figure 1. In this work, all the permeances shown as a single gray-labeled point represent the average permeance measured at WPI over 100 h. The $\mathrm{H}_{2}$ permeance under $\mathrm{H}_{2} / \mathrm{N}_{2}$ atmosphere is shown with the series filled in white, while permeance under hydrogen enriched syngas is shown in solid-black series. Membranes M- $02^{* * *}$ and M- 
$06^{* * *}$ were used in CMRs to perform the WGS with only $\mathrm{CO}, \mathrm{CO}_{2}, \mathrm{H}_{2}$ and $\mathrm{H}_{2} \mathrm{O}$ present. Their $\mathrm{H}_{2}$ permeance was measured before and after the reaction. The reaction proceeded for $450 \mathrm{~h}$ and $390 \mathrm{~h}$ for $\mathrm{M}-02^{* * *}$ and $\mathrm{M}-06^{* * *}$, respectively [9]. It should be mentioned that $\mathrm{M}-03 \mathrm{~b}^{* *}$ was originally synthesized as a Pd/Au membrane (M-03 ${ }^{*}$ ). However, after testing, M-03* was polished [19] and replated with $2 \mu \mathrm{m}$ of Pd [14]. It was expected that the mechanical treatment removed the Au layer of the membrane. However, due to intermetallic diffusion, traces of Au might still be present in the membrane or in the support. Therefore, its characteristics [14] were used only for comparison purposes and its permeance was not included in Figure 1.

M-04* showed an initial $\mathrm{H}_{2}$ permeance of $23.2 \mathrm{Nm}^{3} \mathrm{~m}^{-2} \mathrm{~h}^{-1} \mathrm{bar}^{-0.5}$ at WPI. At NCCC however, afterwards the flow rapidly declined to $11.6 \mathrm{Nm}^{3} \mathrm{~m}^{-2} \mathrm{~h}^{-1} \mathrm{bar}^{-0.5}$ and further down to $8.1 \mathrm{Nm}^{3} \mathrm{~m}^{-2} \mathrm{~h}^{-1} \mathrm{bar}^{-0.5}$ after $200 \mathrm{~h}$. The hydrogen permeance experienced a drop of 55\% compared to its initial value. After removal, the surface of the membrane was covered with a thick black layer.

The permeance of M-10 at $450^{\circ} \mathrm{C}$ measured at WPI under pure $\mathrm{H}_{2}$ was $29.2 \mathrm{Nm}^{3} \mathrm{~m}^{-2} \mathrm{~h}^{-1}$ bar $^{-0.5}$ with a $\mathrm{H}_{2} / \mathrm{He}$ selectivity > 2500. At NCCC, M-10 was tested for a total of $230 \mathrm{~h}$ under $\mathrm{H}_{2} / \mathrm{N}_{2}$ and syngas atmosphere. The membrane first dwelt under $\mathrm{H}_{2} / \mathrm{N}_{2}$ where the $\mathrm{H}_{2}$ permeance declined compared to the value measured under pure $\mathrm{H}_{2}$ at WPI. After $40 \mathrm{~h}$ under $\mathrm{H}_{2} / \mathrm{N}_{2}$, the average permeance decreased by $70 \%$. Upon syngas introduction, no significant decrease of the $\mathrm{H}_{2}$ permeance was observed indicating that $\mathrm{H}_{2}$ permeance inhibition (mostly due to surface contamination) occurred in the $\mathrm{H}_{2} / \mathrm{N}_{2}$ mixture. The permeance of M-10 membrane was $5.8 \mathrm{Nm}^{3} \mathrm{~m}^{-2} \mathrm{~h}^{-1} \mathrm{bar}^{-0.5}$ and remained constant in syngas for $120 \mathrm{~h}(80 \%$ loss compared to the level observed at WPI). After this time, the flow started to increase abruptly indicating the opening of pinholes resulting in a loss in selectivity.

As previously reported [14], the WPI permeance of $\mathrm{M}-03 \mathrm{~b}^{* *}$ was $17.7 \mathrm{Nm}^{3} \mathrm{~m}^{-2} \mathrm{~h}^{-1} \mathrm{bar}^{-0.5}$. The membrane showed a permeance drop to $11.1 \mathrm{Nm}^{3} \mathrm{~m}^{-2} \mathrm{~h}^{-1} \mathrm{bar}^{-0.5}$ under syngas. The permeance drop corresponded to $37 \%$ of the original permeance. This reduction in permeance was significantly lower than that of M-04* and M-10. It is important to notice that the membrane thickness of M-03b ${ }^{* *}$ was the same as M-10 but thinner than M-04*. This meant that the permeance drop observed in these membranes did not depend on the thickness of the Pd layer and was mainly due to surface contamination. The lower permeance drop in $\mathrm{M}-03 \mathrm{~b}^{* *}$ could be attributed to the presence of Au traces within the Pd structure and/or the support.

Before being tested as CMRs, M- $02^{* * *}$ and $\mathrm{M}-06^{* * *}$ were tested at $420^{\circ} \mathrm{C}$ and displayed $\mathrm{H}_{2}$ permeances of 21.7 and $21.9 \mathrm{Nm}^{3} \mathrm{~m}^{-2} \mathrm{~h}^{-1} \mathrm{bar}^{-0.5}$, respectively [9]. The WGS reaction took place for $450 \mathrm{~h}$ and $390 \mathrm{~h}$ for M$02^{* * *}$ and $\mathrm{M}-06^{* * *}$, respectively. After the reaction, the membranes had $\mathrm{H}_{2}$ permeances of 18.9 and 19.4 $\mathrm{Nm}^{3} \mathrm{~m}^{-2} \mathrm{~h}^{-1} \mathrm{bar}^{-0.5}$, respectively. This corresponded to a permeance drop of $13 \%$ and $11 \%$, respectively. As our group reported previously [9], the reason for the permeance decline was due to intermetallic diffusion caused by uneven temperature distribution, which was higher than $450^{\circ} \mathrm{C}$, and not because of the presence 
of $\mathrm{CO}, \mathrm{CO}_{2}$ and $\mathrm{H}_{2} \mathrm{O}$. The permeance drop under syngas of MA- $04^{*}$ and MA-10 was significantly larger than that of $\mathrm{M}-02^{* * *}$ and $\mathrm{M}-06^{* * *}$ and this phenomenon occurred within a shorter period of time. This behavior suggested that the presence of $\mathrm{CO}, \mathrm{CO}_{2}$ and $\mathrm{H}_{2} \mathrm{O}$ did not affect the stability of pure $\mathrm{Pd}$ membranes and that the permeance drop was caused by the presence of other contaminants.

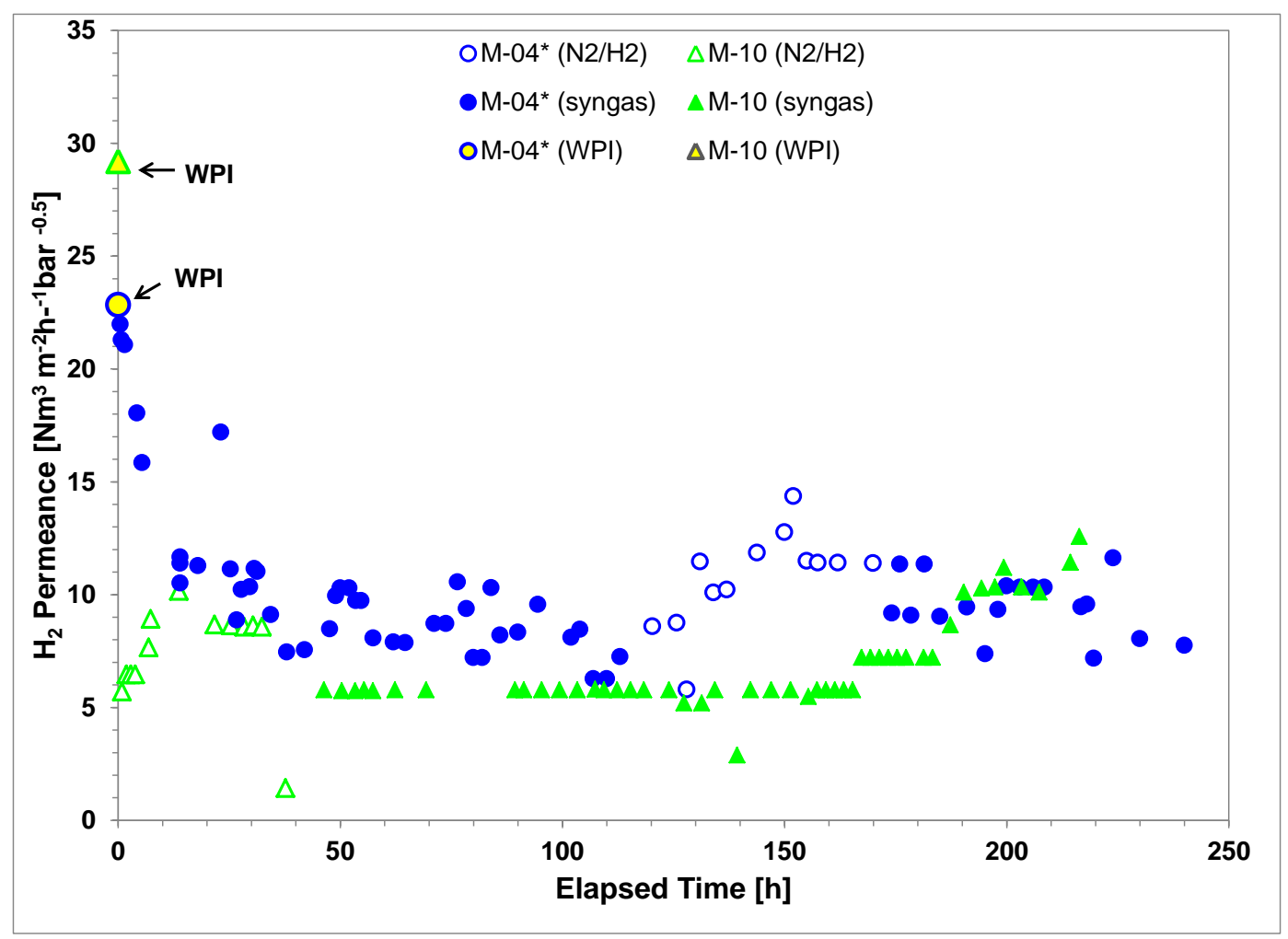

Figure 1. $\mathrm{H}_{2}$ Permeance of pure Pd membranes as a function of time.

The $\mathrm{H}_{2}$ purity profiles of pure M-04 ${ }^{*}$ and M-10 are shown in Figure 2. The hydrogen purity of M-10 under syngas was $99.7 \%$ that remained constant for $120 \mathrm{~h}$; the purity decreased however to $77.9 \%$ after $227 \mathrm{~h}$. The $\mathrm{H}_{2}$ purity of M-10 did not seem to depend on the gas composition. M-04* had a more stable purity profile throughout the test with an average value of $\sim 98 \%$. The $\mathrm{H}_{2}$ purity was $>99.2 \%$ at the beginning of the test and declined to $96.8 \%$ after $240 \mathrm{~h}$. The purity of M- $04^{*}$ seemed to be lower under $\mathrm{H}_{2} / \mathrm{N}_{2}$ mixed gas than that under syngas conditions. M-04* was more robust and had longer stability under syngas conditions than M-10. The permeance of M-04* decreased by $50 \%$ from its original value while M-10 decreased by $75 \%$. The reason was the thicker dense Pd film of M- $04^{*}(13.1 \mu \mathrm{m})$ when compared to that of M-10 $(9.6 \mu \mathrm{m})$. It is important to mention that although the permeance of these membranes dropped considerably, their performance was still competitive. According to Oyama et al. [25] membranes with 
permeances $>6 \mathrm{Nm}^{3} \mathrm{~m}^{-2} \mathrm{~h}^{-1}$ bar $^{-0.5}$ and with $\mathrm{H}_{2} / \mathrm{N}_{2}$ selectivities $>1000$ are within or above a Robeson upper boundary limit of Pd membranes.

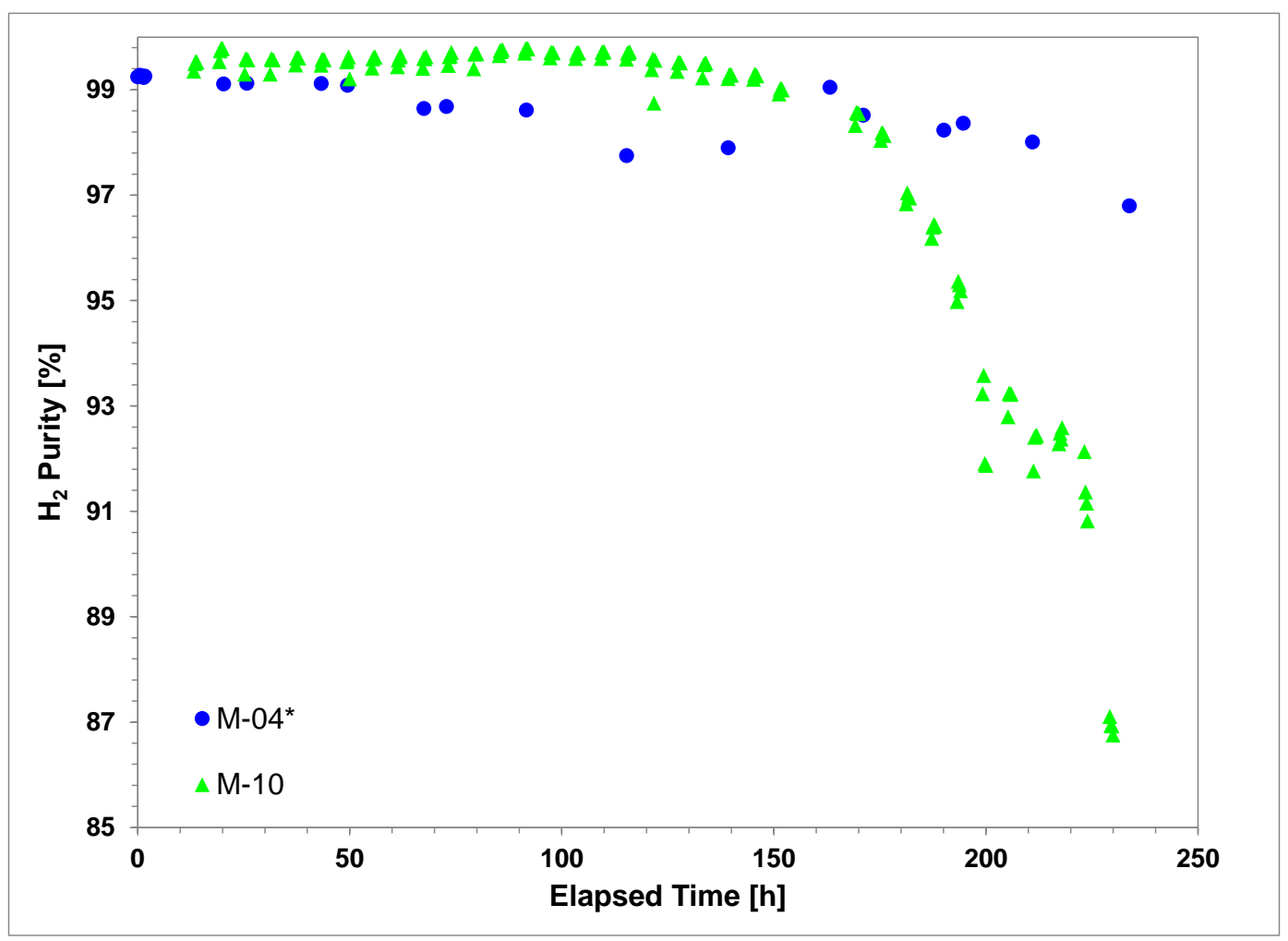

Figure 2. $\mathrm{H}_{2}$ Purity produced by pure $\mathrm{Pd}$ membranes as a function of time.

Although, the previous Pd membranes showed an $\mathrm{H}_{2}$ purity drop under syngas; $\mathrm{M}-03 \mathrm{~b}^{* *}$ had $\mathrm{H}_{2}$ purities greater than $99.4 \%$ that remained constant for $175 \mathrm{~h}$ [14]. The performance of M-03b ${ }^{*}$ is an exception of the already seen Pd membranes suggesting that the previously deposited Au still affected the performance of this membrane.

Pure Pd membranes failed after $\sim 200 \mathrm{~h}$ of operation under syngas conditions. The harsh environment reduced their stability causing the formation of pinholes on the surface of the membrane as shown in Figure 3. The SEM picture shows the surface morphology of M-10 in the deteriorated area. The presence of a crack caused by the long-term exposure of syngas or $\mathrm{H}_{2} \mathrm{~S}$ could be clearly seen. These defects appeared to a lower extent in M-04* because of its thicker Pd layer. Studies on Pd membranes were usually conducted for short periods of time under clean gas conditions [26,27]. However, as demonstrated here, it was necessary to test the membranes for a minimum of $200 \mathrm{~h}$ under industrial conditions to ensure their stability. Ryi et al. [28] attempted to increase the stability of pure Pd membranes within this timeframe. They showed that pure Pd membranes tested under pure $\mathrm{H}_{2}$ conditions tended to fail before 
200 h. Furthermore, the $\mathrm{H}_{2}$ purity produced by $\mathrm{M}-06^{* * *}$ [9] was $99.97 \%$ at 15 bar, but declined when the pressure was increased to 20 bar. This suggested the existence of pinholes that allow more impurities to penetrate the Pd layer at higher pressures.

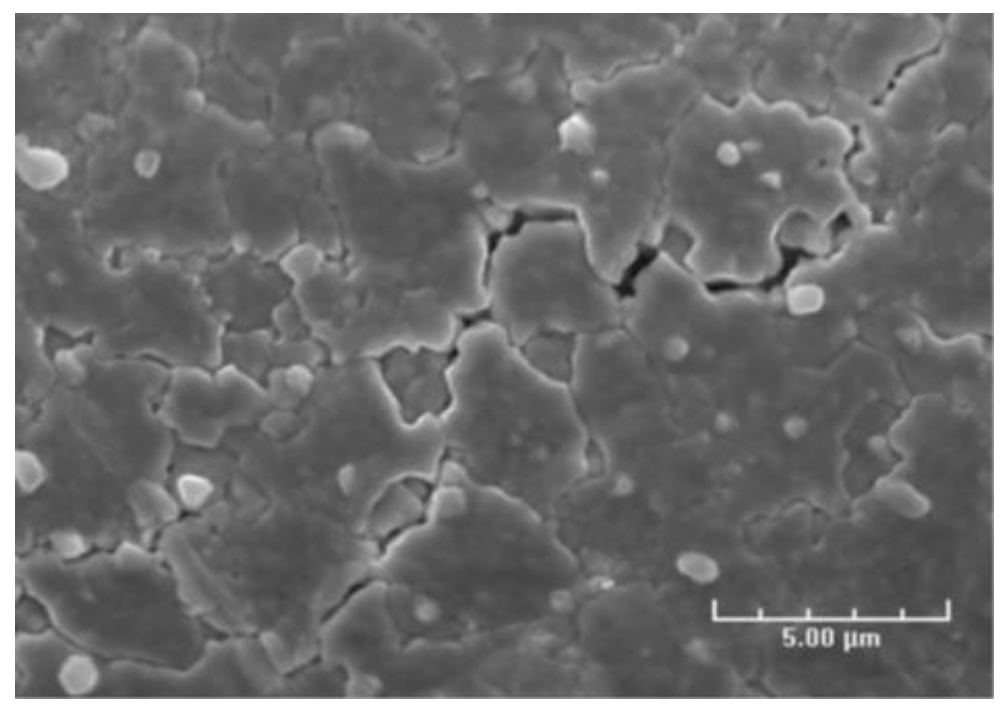

Figure 3. SEM image of a crack formed at the Pd surface layer of M-10.

\subsection{Group 2. Pd/Au Membranes}

Group 2 is composed of asymmetric composite membranes formed by $\mathrm{Pd}$ and on top a layer of $\mathrm{Au}$. Different thicknesses, shown in Table 3, were used for testing the features of these membranes. M- $01^{*}$ had a dense Pd layer of about $8.2 \mu \mathrm{m}$ thickness with a topmost layer of Au with a thickness of $0.16 \mu \mathrm{m}$. M-03 ${ }^{*}$ had a Pd thickness of $10 \mu \mathrm{m}$ and $0.2 \mu \mathrm{m}$ of Au. M-07 ${ }^{* *}$ consisted of an $8.7 \mu \mathrm{m}$ Pd layer and an 0.5 $\mu \mathrm{m}$ Au layer. Both $\mathrm{M}-01^{*}$ and $\mathrm{M}-07^{* *}$ had a similar palladium thickness but different amounts of Au for comparison. Membrane M-04b consisted of a dense $14 \mu \mathrm{m}$ Pd layer and was additionally covered with an $0.9 \mu \mathrm{m}$ Au layer. Notice that M-04b was designated as M-04 before Au was deposited and was tested as a pure Pd membrane in the previous section. M-04b had a similar Au load as M-07** but twice as much Pd. Finally, M-11 consisted of a dense Pd layer of only $5 \mu \mathrm{m}$ covered with an $0.8 \mu \mathrm{m}$ Au layer and an $0.9 \mu \mathrm{m}$ Pd layer on top of the Au layer.

Table 3. Pd-Au asymmetric membrane composition.

\begin{tabular}{|c|c|}
\hline $\begin{array}{c}\text { Membrane } \\
\text { Nomenclature }\end{array}$ & Composition / $\boldsymbol{\mu m}$ \\
\hline $\mathrm{M}^{*} 01^{*}$ & $8.2(\mathrm{Pd})+0.16(\mathrm{Au})$ \\
\hline $\mathrm{M}^{*}-3^{* * *}$ & $10(\mathrm{Pd})+0.2(\mathrm{Au})$ \\
\hline $\mathrm{M}-07^{* *}$ & $8.7(\mathrm{Pd})+0.5(\mathrm{Au})$ \\
\hline $\mathrm{M}-04 \mathrm{~b}$ & $14(\mathrm{Pd})+0.9(\mathrm{Au})$ \\
\hline $\mathrm{M}-11$ & $5(\mathrm{Pd})+0.8(\mathrm{Au})+0.9(\mathrm{Pd})$ \\
\hline
\end{tabular}


The permeance of the $\mathrm{Pd} / \mathrm{Au}$ membranes was tested under $\mathrm{H}_{2} / \mathrm{N}_{2}$ mixture and syngas atmospheres. Figure 4 shows the permeance of these membranes as a function of time. The permeance of the membranes under $\mathrm{H}_{2} / \mathrm{N}_{2}$ mixture and under syngas is shown for all membranes including the WPI permeance shown as a single gray-labeled point.

M-01 ${ }^{*}$ showed an initial permeance at WPI of $28.2 \mathrm{Nm}^{3} \mathrm{~m}^{-2} \mathrm{~h}^{-1} \mathrm{bar}^{-0.5}$ and dropped to $21 \mathrm{Nm}^{3} \mathrm{~m}^{-2} \mathrm{~h}^{-1} \mathrm{bar}^{-0.5}$ under $\mathrm{H}_{2} / \mathrm{N}_{2}$ and to $8.5 \mathrm{Nm}^{3} \mathrm{~m}^{-2} \mathrm{~h}^{-1} \mathrm{bar}^{-0.5}$ under syngas [6]. M-07 $7^{* * *}$ had a WPI permeance of $29.2 \mathrm{Nm}^{3} \mathrm{~m}^{-2} \mathrm{~h}^{-}$ ${ }^{1}$ bar $^{-0.5}$. Under $\mathrm{H}_{2} / \mathrm{N}_{2}$ atmosphere, the membrane showed a permeance of $9.5 \mathrm{Nm}^{3} \mathrm{~m}^{-2} \mathrm{~h}^{-1} \mathrm{bar}^{-0.5}$. The permeance increased after switching to syngas, and then decreased to reach a steady average permeance of $13 \mathrm{Nm}^{3} \mathrm{~m}^{-2} \mathrm{~h}^{-1} \mathrm{bar}^{-0.5}$. M-0 $7^{* * *}$ was tested for $470 \mathrm{~h}$ producing $0.63 \mathrm{~kg}$ of $\mathrm{H}_{2}$ per day at the end of testing. M-04b had a WPI permeance of $11.4 \mathrm{Nm}^{3} \mathrm{~m}^{-2} \mathrm{~h}^{-1} \mathrm{bar}^{-0.5}$ with a $\mathrm{H}_{2} / \mathrm{He}$ selectivity >2700. This $\mathrm{Pd} / \mathrm{Au}$ membrane was tested for $250 \mathrm{~h}$ under $\mathrm{H}_{2} / \mathrm{N}_{2}$ mixtures and syngas atmospheres. After $40 \mathrm{~h}$ in $\mathrm{H}_{2} / \mathrm{N}_{2}$ mixture, the permeance had a steady permeance which corresponded to a $25 \%$ decrease in permeance. Upon syngas introduction, the $\mathrm{H}_{2}$ permeance decreased $37 \%$.

M-11 showed a WPI permeance of $22.7 \mathrm{Nm}^{3} \mathrm{~m}^{-2} \mathrm{~h}^{-1} \mathrm{bar}^{-0.5}$ with a $\mathrm{H}_{2} / \mathrm{He}$ selectivity $>2207$. M-11 was tested for a total of $350 \mathrm{~h}$. The $\mathrm{H}_{2}$ permeance of $\mathrm{M}-11$ declined by $36 \%$ under an $\mathrm{H}_{2} / \mathrm{N}_{2}$ mixture and, upon the introduction of syngas, it gradually decreased further. M- $03^{*}$ was not tested under pure $\mathrm{H}_{2}$ at WPI therefore its permeance was not included in Figure 4. However, its permeance was the same under $\mathrm{H}_{2} / \mathrm{N}_{2}$ and syngas $\left(17.6 \mathrm{Nm}^{3} \mathrm{~m}^{-2} \mathrm{~h}^{-1} \mathrm{bar}^{-0.5}\right)$ conditions. The membrane remained stable for $100 \mathrm{~h}$, but an increase in $\mathrm{H}_{2}$ flux occurred along with a large leak [6].

Similar to pure Pd membranes, $\mathrm{Pd} / \mathrm{Au}$ membranes exhibited an initial drop in permeance as soon as they came in contact with the $\mathrm{N}_{2} / \mathrm{H}_{2}$ mixture. This phenomenon supported the fact that some contaminants were adsorbed on the piping walls and stripped out with the hot $\mathrm{N}_{2} / \mathrm{H}_{2}$ mixture. The $\mathrm{Au}$ content on the membranes reduced the $\mathrm{H}_{2}$ permeance. For instance, $\mathrm{M}-07^{* *}$ with a thinner Au layer $(0.5 \mu \mathrm{m})$ displayed a permeance $40 \%$ greater than M-04b $(0.9 \mu \mathrm{m})$. In the case of M-04b and M-11, both membranes had a similar Au load; however, M-11 had an upper Pd layer, which could have improved its permeance. Additionally, it is important to notice that M-11 had a thinner Pd layer. M-04b was subjected to syngas atmosphere and $\mathrm{H}_{2} \mathrm{~S}$ treatments after $120 \mathrm{~h}$ of testing. $\mathrm{H}_{2} \mathrm{~S}$ was introduced at a concentration of $10.6 \mathrm{ppm}$ leading to a reduction of $\mathrm{H}_{2}$ permeance to $3 \mathrm{Nm}^{3} \mathrm{~m}^{-2} \mathrm{~h}^{-1} \mathrm{bar}^{-0.5}$. After $200 \mathrm{~h}$, the $\mathrm{H}_{2} \mathrm{~S}$ input was stopped and the membrane recovered its initial $\mathrm{H}_{2}$ permeance of $7.2 \mathrm{Nm}^{3} \mathrm{~m}^{-2} \mathrm{~h}^{-1} \mathrm{bar}^{-0.5}$ in about 30 minutes.

The addition of $\mathrm{Au}$ did not seem to affect the initial WPI permeance when compared with pure Pd membranes. The reason was that the active sites of the Pd layer were available for $\mathrm{H}_{2}$. Gold did not seem to block these sites, suggesting that intermetallic diffusion of Au into Pd occurred. In addition, it could be seen that $\mathrm{Pd} / \mathrm{Au}$ membranes experienced a fast loss in permeance at first, most probably due to the adsorption of unknown contaminants on the surface and no further significant permeance loss occurred 
indicating a low or negligible bulk contamination. Surface poisoning, as previously described by Chen and $\mathrm{Ma}$ [13] affected the permeance of the membrane in two stages: surface and bulk sulfidation. First, the surface of the membrane was contaminated by $\mathrm{H}_{2} \mathrm{~S}$, failing to separate $\mathrm{H}_{2}$. This was evidenced by the initial decrease in permeance (from the permeance measured at WPI to the initial sulfur exposure). The second stage involved the bulk deterioration of the Pd film, which in the case of $\mathrm{Pd} / \mathrm{Au}$ was not present causing no further permeance drop.

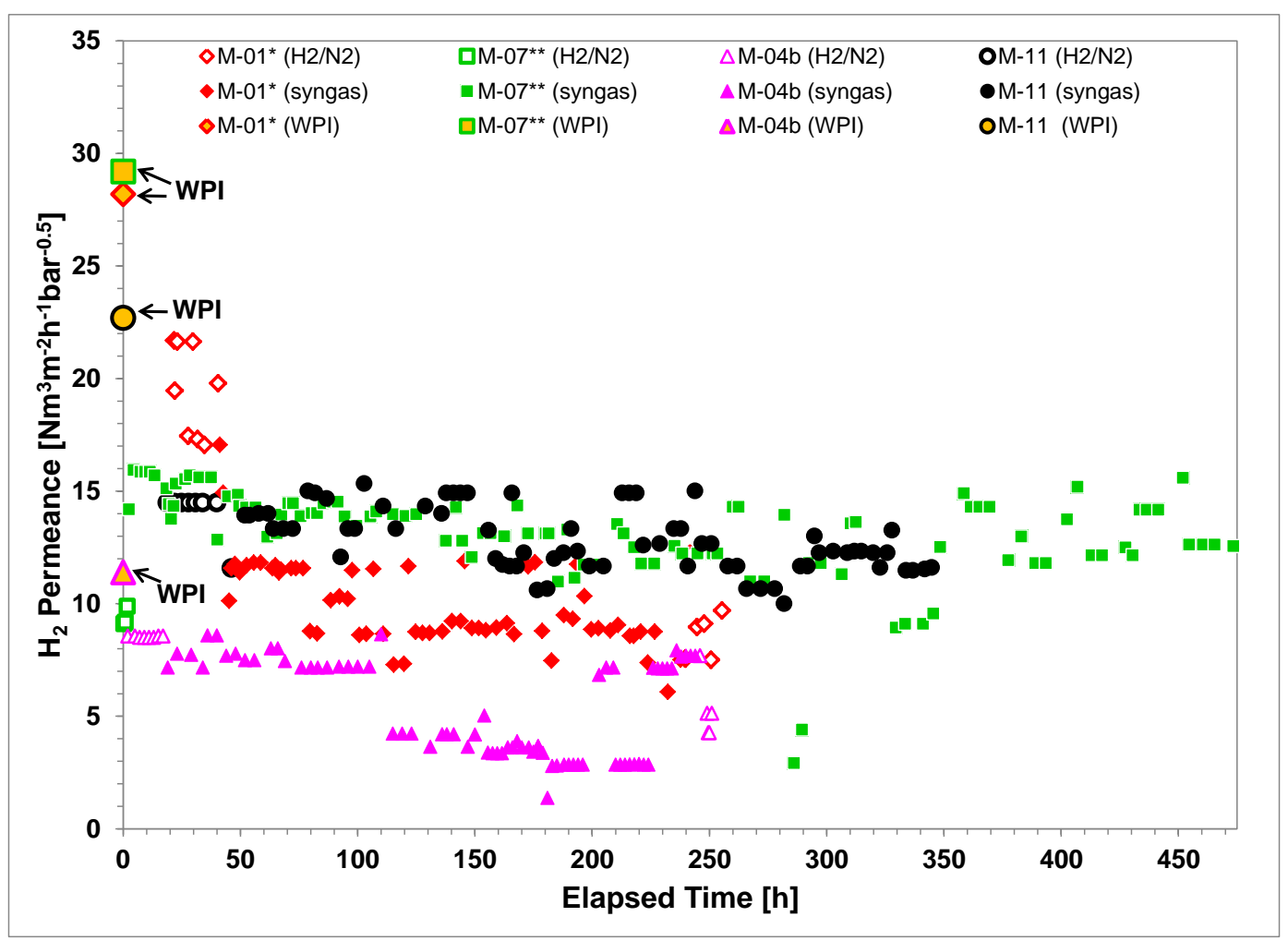

Figure 4. $\mathrm{H}_{2}$ Permeance of $\mathrm{Pd} / \mathrm{Au}$ membranes as a function of time.

The purity of the $\mathrm{Pd} / \mathrm{Au}$ membranes was more stable throughout the test as shown in Figure 5. The $\mathrm{H}_{2}$ permeance of the $\mathrm{Pd} / \mathrm{Au}$ membranes did not depend on whether the feed gas was $\mathrm{H}_{2} / \mathrm{N}_{2}$ or syngas. The $\mathrm{H}_{2}$ purity produced by the M- $01^{*}$ membrane stayed above $99.89 \%$ during the entire $220 \mathrm{~h}$ of testing. After removal from the test, no carbonaceous deposit was observed on the membrane surface. M- $07^{* *}$ had a rather stable purity $\sim 99.9 \%$ throughout the measurements. M-04b showed that the introduction of $\mathrm{H}_{2} \mathrm{~S}$ between $120 \mathrm{~h}$ and $200 \mathrm{~h}$ had no effect on $\mathrm{H}_{2}$ purity. The resulting $\mathrm{H}_{2}$ purity under syngas during $250 \mathrm{~h}$ was $>99.5 \%$. M-11 had a stable $\mathrm{H}_{2}$ purity profile of $99.5 \%$. These results showed that $\mathrm{Pd} / \mathrm{Au}$ membranes were stable in a syngas atmosphere for over $200 \mathrm{~h}$, in contrast with pure Pd membranes. 
Under syngas, the $\mathrm{H}_{2}$ purity produced by these membranes remained constant, but the permeance decreased. This suggested that the active sites of the surface became poisoned at first, decreasing the $\mathrm{H}_{2}$ permeance. In the case of pure Pd membranes, the bulk Pd layer was further poisoned, damaging it and generating defects. However, for Pd/Au membranes, while the surface became contaminated, Au diffused towards the defects on the bulk preventing the development of pinholes. Indeed, Au seemed to fill and cover any pinholes or defects produced at the Pd layer, acting as a patch paste.

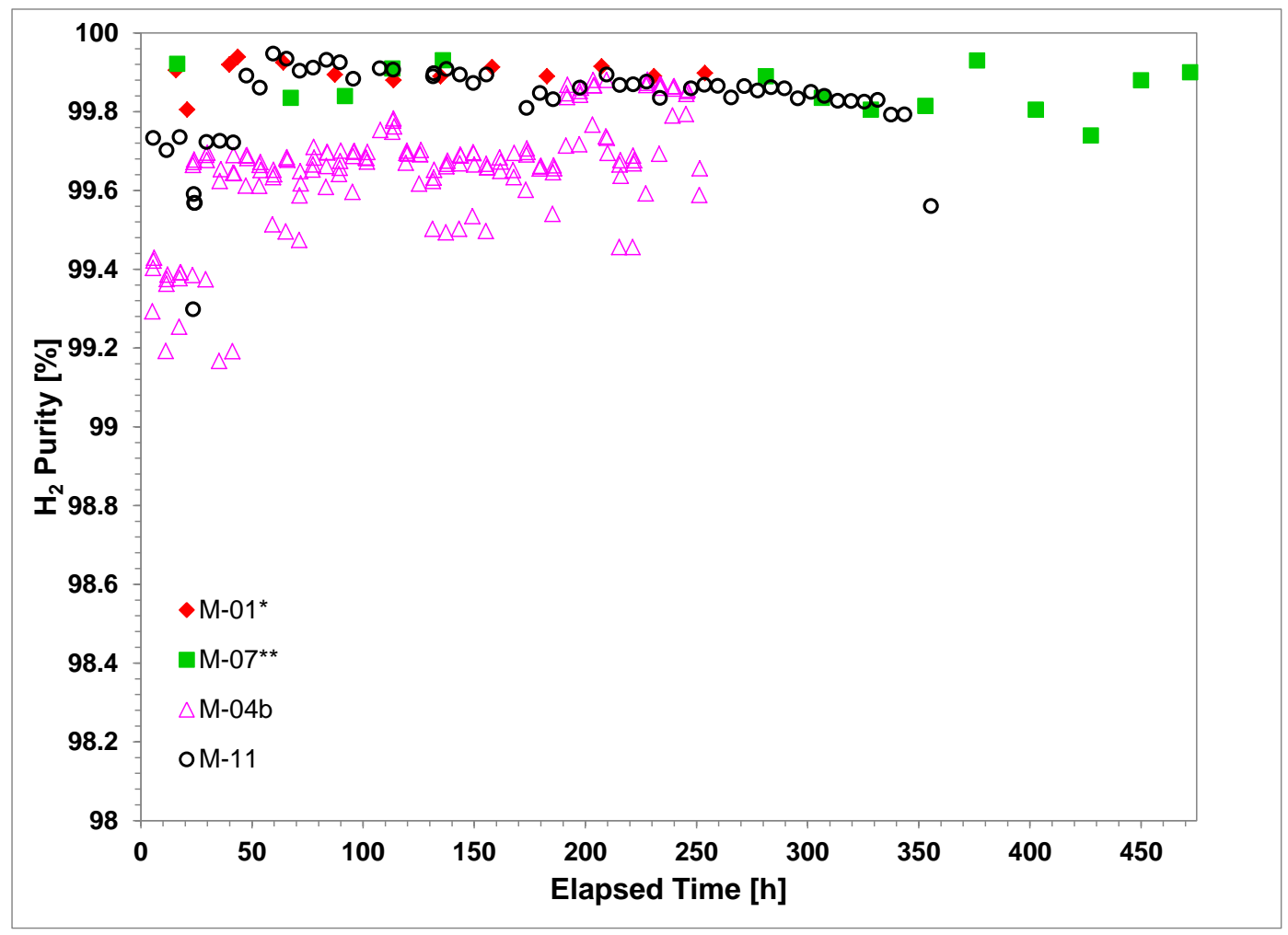

Figure 5. $\mathrm{H}_{2}$ Purity produced by of $\mathrm{Pd} / \mathrm{Au}$ membranes as a function of time.

\subsection{Group 3. Pd/Pt Membranes}

Group 3 is composed of asymmetric membranes formed by Pd with Pt on the top. Although few studies have been reported on $\mathrm{Pd} / \mathrm{Pt}$ membranes; it is suggested that $\mathrm{Pt}$ has $\mathrm{H}_{2} \mathrm{~S}$ resistant properties that can be exploited to improve the resistance of Pd/Alloy membranes [29,30,31]. Kajiwara et al. showed a small change on the lattice structure of $\mathrm{Pt}(0.39$ to $0.35 \mathrm{~nm})$ after sulfidation compared to that of $\mathrm{Pd}(0.39$ to $0.65 \mathrm{~nm}$ ) [32]. The reported Pd/Pt membranes had cracks allowing the leak of other gases to pass through. For the purposes of this investigation, two membranes were fabricated with compositions shown in

Table 4. M-12 consisted of a $3.9 \mu \mathrm{m}$ thick dense Pd layer, which was additionally covered, with an 0.5 $\mu \mathrm{m}$ Pt layer and an $0.9 \mu \mathrm{m}$ Pd layer on top of the Pt layer. M-13 membrane was plated with $4.8 \mu \mathrm{m}$ of Pd and $0.45 \mu \mathrm{m}$ of $\mathrm{Pt}$ on top, to produce a $\mathrm{Pd} / \mathrm{Pt}$ asymmetric membrane. Notice that this is the first time that 
the results of a performance assessment of $\mathrm{Pd} / \mathrm{Pt}$ membranes are reported in the literature under actual coal derived syngas.

Table 4. Pd/Pt membrane composition.

\begin{tabular}{|c|c|}
\hline $\begin{array}{c}\text { Membrane } \\
\text { Nomenclature }\end{array}$ & Composition / $\boldsymbol{\mu m}$ \\
\hline $\mathrm{M}-12$ & $4(\mathrm{Pd})+0.5(\mathrm{Pt})+0.9(\mathrm{Pd})$ \\
\hline $\mathrm{M}-13$ & $4.8(\mathrm{Pd})+0.45(\mathrm{Pt})$ \\
\hline
\end{tabular}

Figure 6 shows the $\mathrm{H}_{2}$ permeances at WPI, under $\mathrm{H}_{2} / \mathrm{N}_{2}$ mixture and syngas of the $\mathrm{Pd} / \mathrm{Pt}$ membranes as a function of time. The $\mathrm{H}_{2}$ permeance of M-12 (Pd/Pt/Pd) measured at WPI was $15.7 \mathrm{Nm}^{3} \mathrm{~m}^{-2} \mathrm{~h}^{-1} \mathrm{bar}^{-0.5}$ with a $\mathrm{H}_{2} / \mathrm{He}$ selectivity of 393 . Although, M-12 had a high platinum content close to its surface; it still displayed a high $\mathrm{H}_{2}$ permeance. This $\mathrm{Pd} / \mathrm{Pt} / \mathrm{Pd}$ membrane was tested for a total of $350 \mathrm{~h}$ under $\mathrm{H}_{2} / \mathrm{N}_{2}$ and syngas atmospheres. The membrane first dwelt under $\mathrm{H}_{2} / \mathrm{N}_{2}$ where the permeance declined by $36 \%$. Upon syngas introduction, a slight decrease in permeance was observed reaching a minimum of $8.4 \mathrm{Nm}^{3} \mathrm{~m}^{-2} \mathrm{~h}^{-}$ ${ }^{1}$ bar $^{-0.5}$. At $160 \mathrm{~h}$, the flow started to increase abruptly indicating the opening of pinholes and a loss in selectivity. The feed gas was alternated between $\mathrm{H}_{2} / \mathrm{N}_{2}$ and syngas but the permeance kept increasing independently of the composition of the feed.

The $\mathrm{H}_{2}$ permeance of M-13 measured at WPI was $16.5 \mathrm{Nm}^{3} \mathrm{~m}^{-2} \mathrm{~h}^{-1} \mathrm{bar}^{-0.5}$ with an ideal selectivity of 590 . At NCCC, M-13 was tested for a total of $150 \mathrm{~h}$. The permeance of the membrane declined by $59 \%$ under $\mathrm{H}_{2} / \mathrm{N}_{2}$, as seen in previous membranes. The permeance of $\mathrm{M}-13$ also remained relatively constant in syngas after $150 \mathrm{~h}$ of testing. Unfortunately, the gasifier' operation stopped and further testing was not performed in order to observe whether this Pd/Pt membrane also failed at times $>150 \mathrm{~h}$. Since, M-12 had a Pd layer on top of the Pt film; its $\mathrm{H}_{2}$ permeance was slightly higher than M-13.

The magnitude of the $\mathrm{H}_{2}$ permeance of the $\mathrm{Pd} / \mathrm{Pt}$ membranes was lower when tested at WPI than those composed of pure Pd. This was the result of covering the surface of the Pd layer, where the active sites were located with Pt. Once the membrane became poisoned pure $\mathrm{Pd}$ and $\mathrm{Pd} / \mathrm{Pt}$ membranes showed permeances of the same magnitude. This indicated that while the active sites of the surface of pure Pd membranes became occupied by the contaminant; $\mathrm{Pd} / \mathrm{Pt}$ membranes reduced the effect of the contaminant. Pt might have an effect on reducing poisoning, but further investigation is required. 


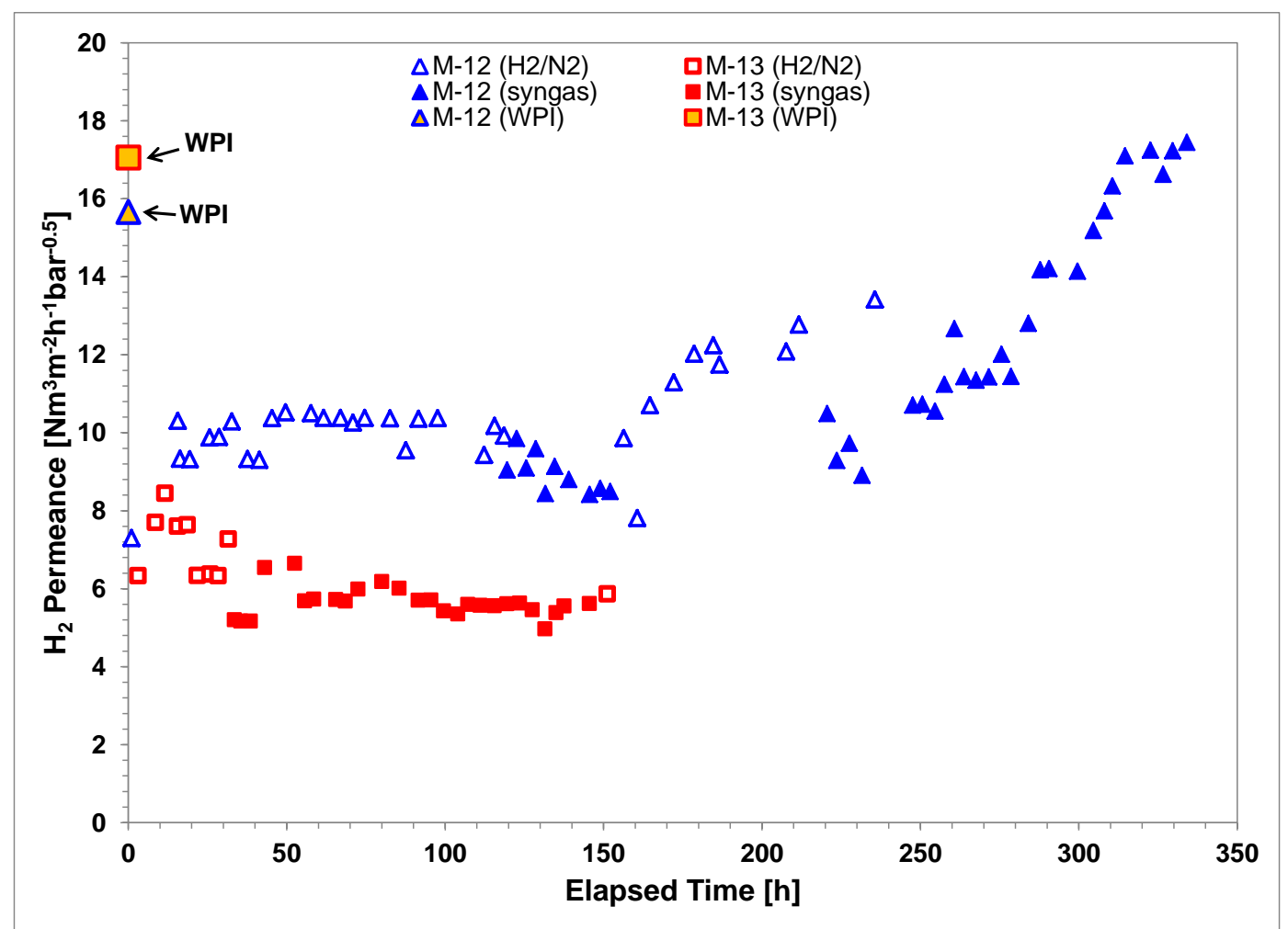

Figure 6. $\mathrm{H}_{2}$ Permeance of $\mathrm{Pd} / \mathrm{Pt}$ membranes as a function of time.

Figure 7 shows the $\mathrm{H}_{2}$ purity of the $\mathrm{Pd} / \mathrm{Pt}$ membranes as a function of time. M-12 showed an initial $\mathrm{H}_{2}$ purity of $98 \%$ that remained stable for $100 \mathrm{~h}$ under $\mathrm{H}_{2} / \mathrm{N}_{2}$. After feeding syngas for about $50 \mathrm{~h}$; the purity of the membrane increased to $99 \%$. At this moment, the $\mathrm{H}_{2} / \mathrm{N}_{2}$ was introduced again, and the purity experienced a steady drop to $93 \%$. The feed gas was changed again to syngas where the purity seemed to recover. However, the decline in purity continued until the end of the test. M-13 was tested for a shorter time period. This membrane was more stable and produced a higher $\mathrm{H}_{2}$ purity than that of $\mathrm{M}-12$. Under $\mathrm{H}_{2} / \mathrm{N}_{2}$ atmosphere the membrane showed an $\mathrm{H}_{2}$ purity of $99 \%$, while under syngas, the membrane produced $\mathrm{H}_{2}$ with a purity of $>99.5 \%$. Notice that the produced $\mathrm{H}_{2}$ purity of M-12 in Figure 7 was similar to M-10 (pure Pd) in Figure 2. Both membranes remained stable for about $150 \mathrm{~h}$ and afterwards, a sudden loss of selectivity occurred. This suggested that Pt did not patch the defects in the Pd layer. 


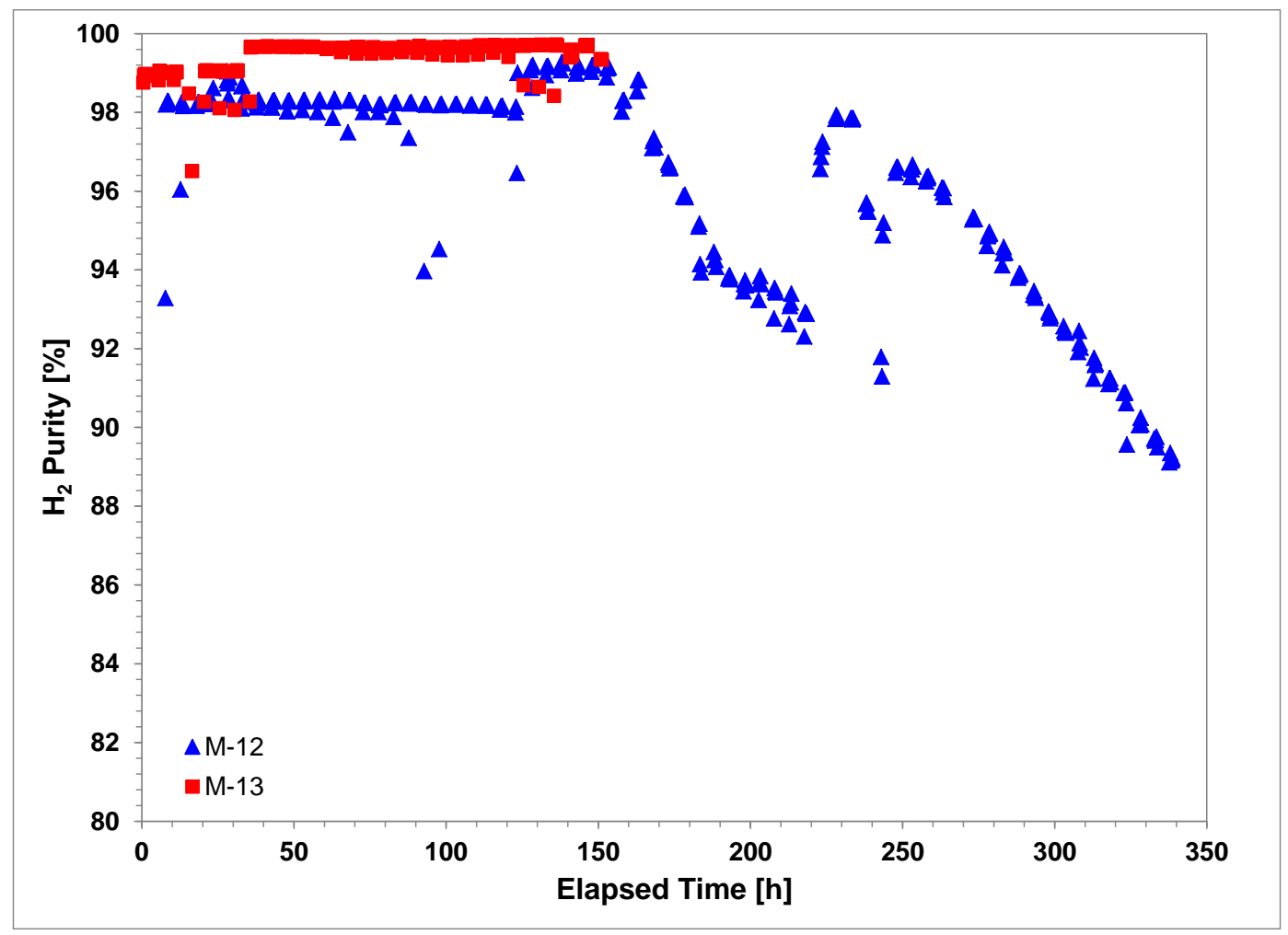

Figure 7. $\mathrm{H}_{2}$ Purity produced by $\mathrm{Pd} / \mathrm{Pt}$ membranes as a function of time.

\subsection{Group 4. Pd/Au/Pt Membranes}

Group 4 is comprised of membranes formed by $\mathrm{Pd}$, $\mathrm{Au}$ and Pt. Ternary alloy membranes such as $\mathrm{Pd} / \mathrm{Cu} / \mathrm{Ni}[33], \mathrm{Pd} / \mathrm{Ag} / \mathrm{Cu}$ [34] and $\mathrm{Pd} / \mathrm{Cu} / \mathrm{Au}$ [35] have been extensively reported. However, performance assessment results of $\mathrm{Pd} / \mathrm{Au} / \mathrm{Pt}$ membranes have never been reported in the pertinent literature. It was expected that the combination of these metals will highlight the properties of Au and Pt in their capacity to enhance the sulfur resistance of the membranes.

Different compositions were used for testing the characteristics of these metals as shown in Table 5. M-08 and M-09 had similar palladium and gold loads (close to $\sim 8.5 \mu \mathrm{m}$ of Pd and $\sim 0.34 \mu \mathrm{m}$ of $\mathrm{Au}$ ), but a different platinum load with $0.1 \mu \mathrm{m}$ and $0.06 \mu \mathrm{m}$, respectively. M-14 membrane had a $10.3 \mu \mathrm{m}$ of Pd, and $0.3 \mu \mathrm{m}$ layer of $\mathrm{Au}$ on top and an $0.09 \mu \mathrm{m}$ layer of Pt.

Table 5. $\mathrm{Pd} / \mathrm{Au} / \mathrm{Pt}$ membrane composition.

\begin{tabular}{|c|c|}
\hline $\begin{array}{c}\text { Membrane } \\
\text { Nomenclature }\end{array}$ & Composition / $\boldsymbol{\mu m}$ \\
\hline M-08 & $8.5(\mathrm{Pd})+0.33(\mathrm{Au})+0.1(\mathrm{Pt})$ \\
\hline $\mathrm{M}-09$ & $8.5(\mathrm{Pd})+0.35(\mathrm{Au})+0.06(\mathrm{Pt})$ \\
\hline $\mathrm{M}-14$ & $10.3(\mathrm{Pd})+0.3(\mathrm{Au})+0.09(\mathrm{Pt})$ \\
\hline
\end{tabular}


The $\mathrm{H}_{2}$ permeances of the $\mathrm{Pd} / \mathrm{Au} / \mathrm{Pt}$ membranes are shown in Figure 8. The $\mathrm{H}_{2}$ permeances measured at WPI are shown in a single- point format as previously indicated, and as a function of time under $\mathrm{H}_{2} / \mathrm{N}_{2}$ and syngas. M-08 displayed a $\mathrm{H}_{2}$ permeance at WPI of $17.4 \mathrm{Nm}^{3} \mathrm{~m}^{-2} \mathrm{~h}^{-1}$ bar $^{-0.5}$ with a $\mathrm{H}_{2} / \mathrm{He}$ selectivity $>1000$. At NCCC, M-08 was tested for $460 \mathrm{~h}$; under $\mathrm{H}_{2} / \mathrm{N}_{2}$, the permeance declined from its initial WPI value. The permeance partially recovered after $13 \mathrm{~h}$ of testing. Upon syngas introduction, the permeance first decreased but remained constant. A gasifier trip occurred and $\mathrm{H}_{2} / \mathrm{N}_{2}$ mixture was introduced to preserve the membrane. Under $\mathrm{H}_{2} / \mathrm{N}_{2}$, the permeance recovered, showing a permeance close to the one measured at WPI. The recovery of the permeance might be the result of the Pt addition, yet this hypothesis needs further verification. Due to the long time needed to repair the gasifier, the membrane was cooled down to room temperature and remained at atmospheric temperature and pressure. After the gasifier was repaired, a second test was started. The membrane dwelt under an $\mathrm{H}_{2} / \mathrm{N}_{2}$ atmosphere and the permeance was similar as before the cooling down. The permeance under syngas was $11 \mathrm{Nm}^{3} \mathrm{~m}^{-2} \mathrm{~h}^{-1} \mathrm{bar}^{-0.5}$ and remained stable. This permeance was similar to the one measured during the first $60 \mathrm{~h}$ in syngas. Unfortunately, a second gasifier trip occurred and the run was terminated.

The $\mathrm{H}_{2}$ permeance of M-09 at WPI was $28.4 \mathrm{Nm}^{3} \mathrm{~m}^{-2} \mathrm{~h}^{-1}$ bar $^{-0.5}$ with a $\mathrm{H}_{2} / \mathrm{He}$ selectivity $>680$. M-09 was tested for a total time of $169 \mathrm{~h}$. The membrane first dwelt under $\mathrm{H}_{2} / \mathrm{N}_{2}$ where the permeance declined compared with its initial WPI value. After $40 \mathrm{~h}$ under $\mathrm{H}_{2} / \mathrm{N}_{2}$ the average permeance decreased by $65 \%$. The introduction of syngas had no significant effect on the permeance. The permeance of M-09 was 9.5 $\mathrm{Nm}^{3} \mathrm{~m}^{-2} \mathrm{~h}^{-1} \mathrm{bar}^{-0.5}$ and remained constant after $123 \mathrm{~h}$ under syngas. The feed was switched back to $\mathrm{H}_{2} / \mathrm{N}_{2}$ where the membrane exhibited the same permeance as before feeding with syngas.

The WPI permeance of M-14 was $22 \mathrm{Nm}^{3} \mathrm{~m}^{-2} \mathrm{~h}^{-1} \mathrm{bar}^{-0.5}$ with an ideal selectivity of 732 . At NCCC, M-14 was tested for $718 \mathrm{~h}$. The membrane first dwelt under $\mathrm{H}_{2} / \mathrm{N}_{2}$ where the permeance decreased compared to the levels previously measured at WPI. Under $\mathrm{H}_{2} / \mathrm{N}_{2}$, the average permeance had a permeance drop of $60 \%$. Syngas was fed afterwards and maintained for $578 \mathrm{~h}$. During the first $200 \mathrm{~h}$ the $\mathrm{H}_{2}$ permeance increased slightly followed by a sustained average permeance of $10.5 \mathrm{Nm}^{3} \mathrm{~m}^{-2} \mathrm{~h}^{-1} \mathrm{bar}^{-0.5}$ until the end of the test.

Compared to pure Pd membranes, the ternary alloy displayed WPI permeances with a similar magnitude. Although, Pt slightly reduced the permeance of the Pd/Pt membranes; its effect was not evident in this group. The difference was due to the smaller amount of Pt deposited onto these ternary membranes. Au, on the other hand, did not seem to interfere with active sites of the Pd layer. Furthermore, compared with pure $\mathrm{Pd}$ membranes, the permeance of $\mathrm{Pd} / \mathrm{Au} / \mathrm{Pt}$ membranes did not deteriorate with time. The effect could be attributed to the Au present in the membranes. 


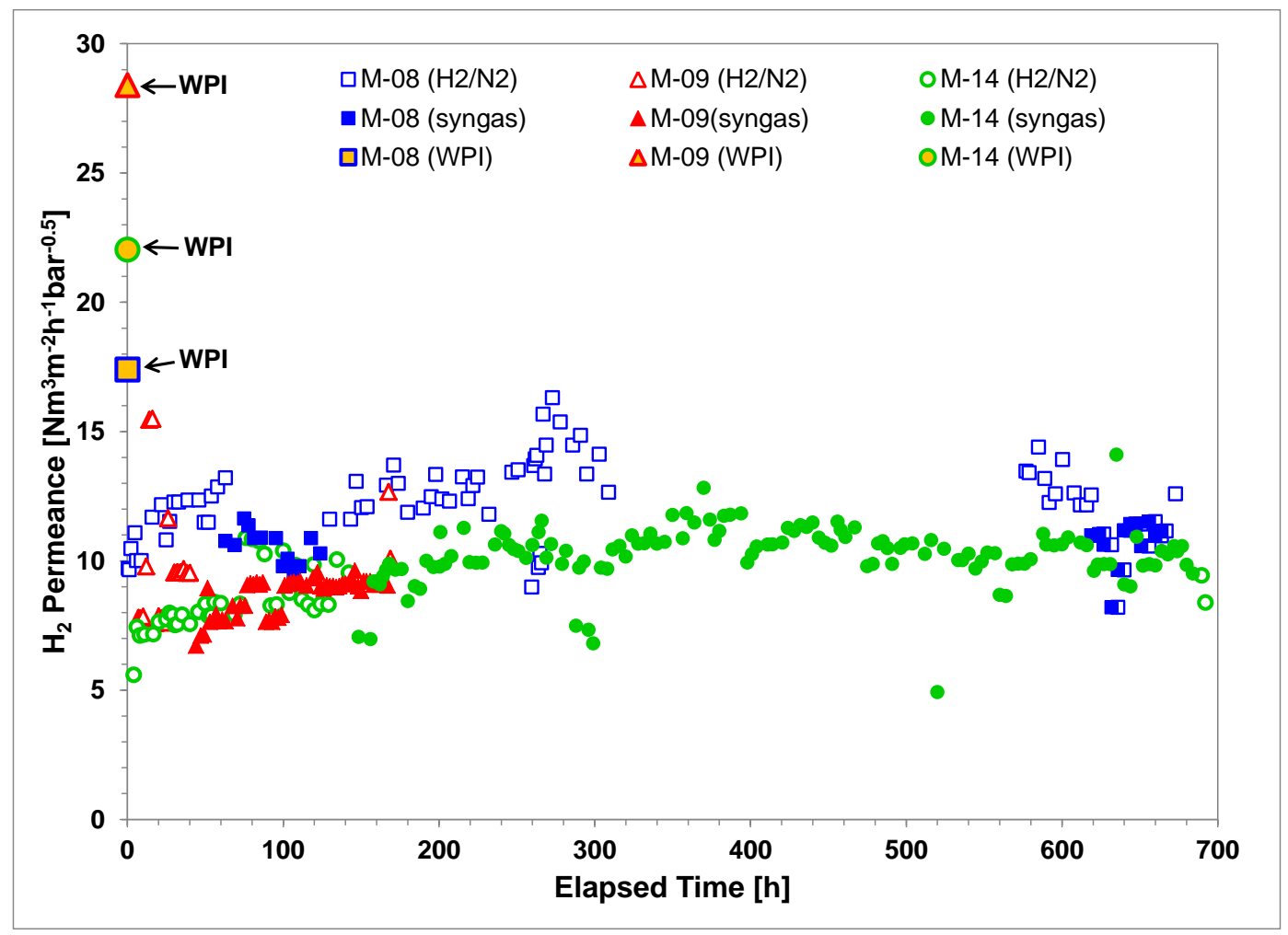

Figure 8. $\mathrm{H}_{2}$ Permeance of $\mathrm{Pd} / \mathrm{Au} / \mathrm{Pt}$ membranes as a function of time.

The purity produced by the $\mathrm{Pd} / \mathrm{Au} / \mathrm{Pt}$ membranes is shown in Figure 9 . M-08 produced $\mathrm{H}_{2}$ with a purity of $>99.8 \%$ throughout the test. The $\mathrm{H}_{2}$ purity produced by M-09 was higher under syngas than the purity under $\mathrm{H}_{2} / \mathrm{N}_{2}$. For instance, the average purity of the $\mathrm{H}_{2}$ produced under $\mathrm{H}_{2} / \mathrm{N}_{2}$ and syngas was 96.9 and $98.8 \%$, respectively. M-14 produced $\mathrm{H}_{2}$ with purity $>99 \%$ but had a slight but steady decline throughout the $700 \mathrm{~h}$ of operation. Notice that the statistical outliers present in the above figure can be attributed to inevitable errors on the experimental measurements involving a rather complex process system such as the one under consideration. However, the main/central trend depicted in the membrane's performance profile is clearly identifiable, thus reliably supporting the aforementioned conclusions.

Compared with pure Pd membranes, the ternary alloy showed superior stability for producing highly pure $\mathrm{H}_{2}$. Although M-09 did not reach a purity of $99 \%$, it remained stable throughout the test. The cause of the lower selectivity of M-09 could be a small defect present in the membrane. This defect did not grow since the $\mathrm{H}_{2}$ purity did not decrease. This suggests that $\mathrm{Au}$ stabilized the pinhole and did not allow its deterioration. The effect of $\mathrm{Pt}$ on this pinhole stabilization could not be concluded since, leak growth was observed in one of the Pd/Pt membranes. 


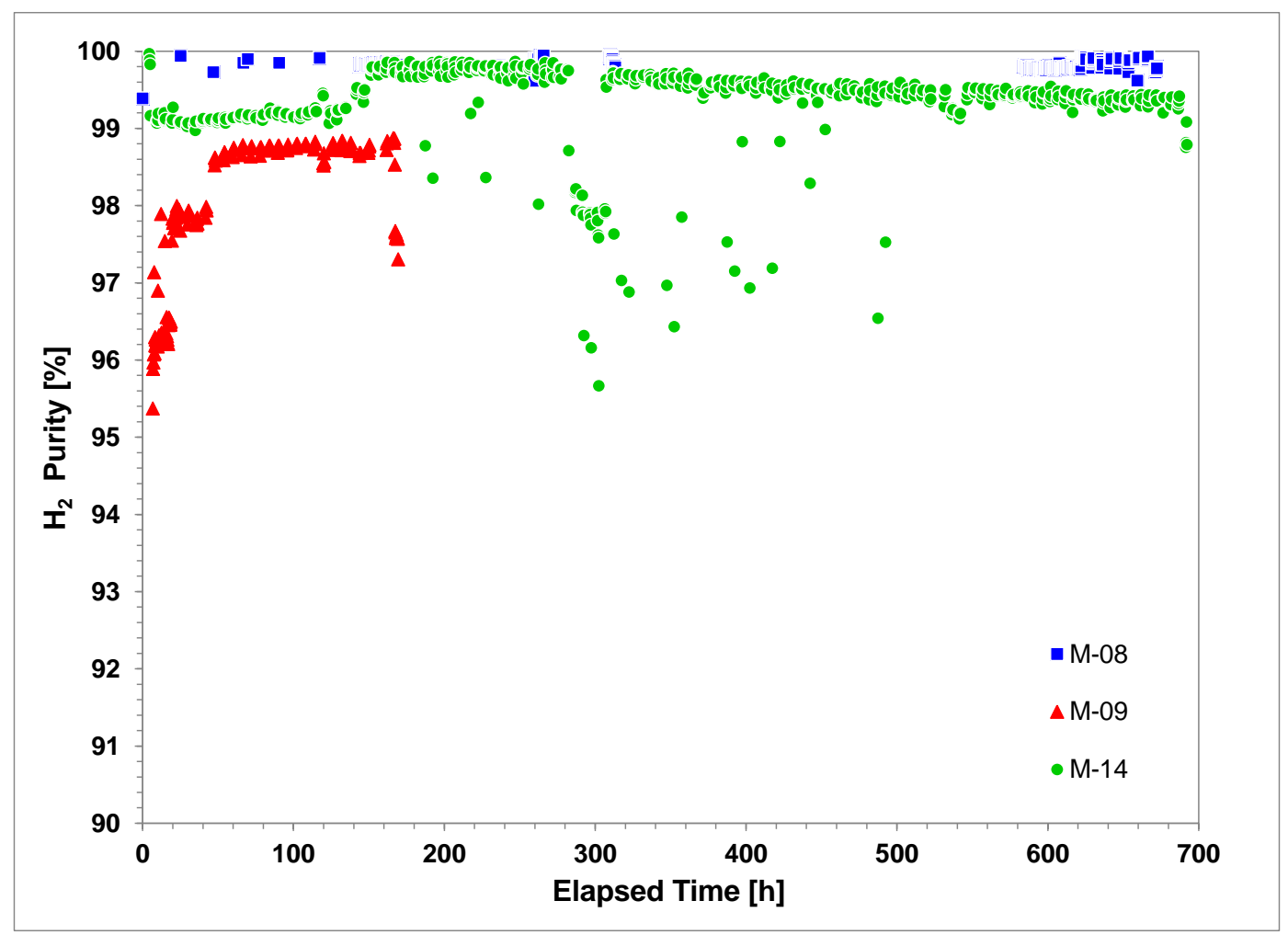

Figure 9. $\mathrm{H}_{2}$ Purity produced by $\mathrm{Pd} / \mathrm{Au} / \mathrm{Pt}$ membranes as a function of time.

\section{Discussion}

\subsection{Overall performance of the Pd and Pd/Alloy membranes}

The performance of the $\mathrm{Pd}, \mathrm{Pd} / \mathrm{Au}, \mathrm{Pd} / \mathrm{Pt}$ and $\mathrm{Pd} / \mathrm{Au} / \mathrm{Pt}$ composite asymmetric membranes under coalderived syngas was evaluated in four categories: $\mathrm{H}_{2}$ permeance, permeance drop compared to the value measured at WPI under pure $\mathrm{H}_{2}$, quality of produced $\mathrm{H}_{2}$, and stability of the membrane. Although, each membrane performed differently, the average value of the Pd and Pd/Alloy groups was used to evaluate their characteristics. Notice that Table 6 shows the characteristics of 11 membranes, which are the most representative for this study.

Permeability was used as a parameter for evaluation, since it provided a better understanding of the intrinsic properties of the material that allowed/promoted hydrogen permeation. Permeability excluded the resistance provided by the thickness of the material. The average permeability of the membranes presented in this work, shown in Table 6, had the following order $\mathrm{Pd}>\mathrm{Pd} / \mathrm{Au} / \mathrm{Pt} \geq \mathrm{Pd} / \mathrm{Au}>\mathrm{Pd} / \mathrm{Pt}$. Pure palladium displayed the highest permeability, while all composite Pd/Alloy membranes showed a reduced permeability. This was reasonable since $\mathrm{Pd}$ was the active material that catalyzed the dissociation and thus the transport of $\mathrm{H}_{2}$. The permeability of the $\mathrm{Pd} / \mathrm{Au}$ membranes under syngas was $19 \%$ lower than that of pure Pd membranes. Platinum seemed to result in a deterioration of the membrane's permeance profile. 
For instance, the $\mathrm{Pd} / \mathrm{Pt}$ membranes displayed the lowest permeability, 58\% lower than pure $\mathrm{Pd}$ membranes. As explained before, Pt blocked the active sites of the Pd layer and therefore resulted in lower activity. For the case of the ternary composite membranes, their $\mathrm{H}_{2}$ permeability decreased by only $11 \%$. The drop in permeability was lower than $\mathrm{Pd} / \mathrm{Pt}$ possibly because of the presence of $\mathrm{Au}$ and the smaller Pt load.

All Pd and Pd/Alloy membranes showed a permeance drop when in contact with the stream containing traces of different contaminants such $\mathrm{Mg}, \mathrm{Na}, \mathrm{Hg}, \mathrm{S}$, etc. These contaminants were previously investigated and were found to be desorbed at the equipment walls [14]. The permeance drop was estimated from the initial permeance displayed at WPI and the average permeance shown at NCCC. The permeance drop due to mass transfer resistance of gas mixtures is negligible and was estimated to be in the range of $0.6-1.6 \%$. The order of membranes, from the lowest permeance drop to the highest, is as follows: $\mathrm{Pd} / \mathrm{Au}>\mathrm{Pd} / \mathrm{Pt}>\mathrm{Pd} / \mathrm{Au} / \mathrm{Pt}>\mathrm{Pd}$. Pure $\mathrm{Pd}$ membranes showed the highest permeance drop. $\mathrm{Pd} / \mathrm{Au}$ membranes showed the smallest drop followed by $\mathrm{Pd} / \mathrm{Pt}$ and the ternary membranes. These results suggested that adding alloys helped to protect the active sites of the Pd layer from harsh environments. Alloys seemed to hinder some of the sites where the poison attacked the surface of the membrane.

The maximum $\mathrm{H}_{2}$ purities produced under actual syngas conditions by the different membranes had the following order: $\mathrm{Pd} / \mathrm{Au}>\mathrm{Pd} / \mathrm{Au} / \mathrm{Pt}>\mathrm{Pd}>\mathrm{Pd} / \mathrm{Pt}$ as shown in Table 6. The presence of Au improved the $\mathrm{H}_{2}$ selectivity of the membrane by patching any defects or pinholes on the surface of the Pd layer. On the other hand, the $\mathrm{Pd} / \mathrm{Pt}$ showed the lowest $\mathrm{H}_{2}$ purity. The effect of $\mathrm{Pt}$ appeared to be harmful to the production of pure $\mathrm{H}_{2}$. The purity displayed by the ternary composite membrane was similar to $\mathrm{Pd} / \mathrm{Au}$. It seemed that even in small amounts, Au had a positive effect on the membrane.

The stability of the membranes was estimated based on the maximum time where the membranes achieved a consistent purity $>99 \%$ under syngas conditions. Notice that, as shown in Table 6 , the time of stability does not necessarily represent the time when the membrane failed in achieving a purity of $99 \%$. In some cases, this time represented the moment when the test was terminated. For instance, the two tested $\mathrm{Pd}$ membranes failed in achieving this purity at 49.5 and $182.9 \mathrm{~h}$. Therefore, it was considered that pure Pd membranes failed at $182.9 \mathrm{~h}$, which was the maximum time found in this work. Membranes composed of $\mathrm{Pd} / \mathrm{Au}$ did not fail during testing. They always displayed purities $>99 \%$, so the sole limitation was the testing time. The longest testing time under syngas atmosphere of $\mathrm{Pd} / \mathrm{Au}$ membranes was $471 \mathrm{~h}$. In the case of Pd/Pt membranes, one membrane failed after only $29 \mathrm{~h}$ of testing. The other $\mathrm{Pd} / \mathrm{Pt}$ membrane did not fail, but its testing stopped after $112 \mathrm{~h}$ in syngas. The ternary $\mathrm{Pd} / \mathrm{Au} / \mathrm{Pt}$ membrane showed one failed membrane. This membrane did not reach a purity of $99 \%$ from the beginning of the test. The maximum operating time of $\mathrm{Pd} / \mathrm{Au} / \mathrm{Pt}$ membrane was $535.5 \mathrm{~h}$. Therefore, the stability of the tested composite membranes followed the order of $\mathrm{Pd} / \mathrm{Au}>\mathrm{Pd} / \mathrm{Au} / \mathrm{Pt}>\mathrm{Pd}>\mathrm{Pd} / \mathrm{Pt}$. This 
implied that $\mathrm{Au}$, during intermetallic diffusion, patched the defects that appeared in the Pd layer. Platinum had the opposite effect; it opened cavities within the Pd structure.

Table 6. Characteristics of the different Pd and Pd/Alloy membranes under coal-derived syngas.

\begin{tabular}{|c|c|c|c|c|c|c|}
\hline Type & Membrane & $\begin{array}{c}\text { Permeability } \\
\mathrm{Nm}^{3} \mathrm{~m}^{1} \mathrm{~m}^{-2} \mathrm{~h}^{-1} \text { bar }^{-0.5}\end{array}$ & $\begin{array}{c}\text { Maximum } \\
\mathrm{H}_{2} \text { purity, }\end{array}$ & $\begin{array}{c}\text { Initial } \\
\text { permeance } \\
\text { drop, } \% \text { b) }\end{array}$ & $\begin{array}{c}\text { Time w/ } \\
\text { purity }>99 \%, \\
\mathbf{h}^{\mathrm{c})}\end{array}$ & $\begin{array}{l}\text { Reason of } \\
\text { termination }\end{array}$ \\
\hline \multirow{3}{*}{ Pure Pd } & M-04 & $2.21 \times 10^{-4}$ & 99.26 & 55 & 49.5 & Failed \\
\hline & M-10 & $9.03 \times 10^{-5}$ & 99.73 & 75 & 182.9 & Failed \\
\hline & Average & $1.56 \times 10^{-4}$ & 99.5 & 65 & & \\
\hline \multirow{5}{*}{$\mathrm{Pd} / \mathrm{Au}$} & $\mathrm{M}-01^{*}$ & $1.15 \times 10^{-4}$ & 99.94 & 33 & 198.5 & Stopped \\
\hline & M-07 ${ }^{* *}$ & $1.67 \times 10^{-4}$ & 99.93 & 68 & 471 & Stopped \\
\hline & M-04b & $1.02 \times 10^{-4}$ & 99.88 & 36 & 223 & Stopped \\
\hline & M-11 & $1.19 \times 10^{-4}$ & 99.95 & 38 & 293 & Stopped \\
\hline & Average & $1.29 \times 10^{-4}$ & 99.93 & 44 & & \\
\hline \multirow{3}{*}{$\mathrm{Pd} / \mathrm{Pt}$} & M-12 & $8.89 \times 10^{-5}$ & 99.69 & 34 & 29.3 & Failed \\
\hline & M-13 & $4.09 \times 10^{-5}$ & 99.07 & 59 & 112 & Stopped \\
\hline & Average & $6.49 \times 10^{-5}$ & 99.38 & 46 & & \\
\hline \multirow{4}{*}{$\mathrm{Pd} / \mathrm{Au} / \mathrm{Pt}$} & M-08 & $1.53 \times 10^{-4}$ & 99.91 & 28 & 64.8 & Stopped \\
\hline & M-09 & $1.06 \times 10^{-4}$ & 98.83 & 65 & N/A & Failed \\
\hline & M-14 & $1.55 \times 10^{-4}$ & 99.86 & 61 & 535.5 & Stopped \\
\hline & Average & $1.38 \times 10^{-4}$ & 99.53 & 52 & & \\
\hline
\end{tabular}

a) Permeability was estimated based on the total metal thickness of the membranes and calculated from the permeance under syngas conditions.

b) The initial permeance drop was calculated from the permeance displayed by the membranes under pure $\mathrm{H}_{2}$ vs. the permeance under syngas or $\mathrm{N}_{2} / \mathrm{H}_{2}$ mixture. c) This is the period of time where the membrane displayed a purity $>99 \%$ under syngas conditions.

\subsection{Performance of Au and Pt as membrane composites}

It is important to notice that these results represent the actual performance of the membranes under real industrial conditions and therefore the environment was not controlled as in the laboratory. Therefore, further research investigations are undoubtedly warranted in order to have a more conclusive and sound understanding on the characteristics of these membranes. However, based on the performance of the $\mathrm{Pd} / \mathrm{Au}$ and $\mathrm{Pd} / \mathrm{Au} / \mathrm{Pt}$ membranes shown in this work, the role of $\mathrm{Au}$ appears to be 1) a patching paste that cures the defects present at the surface of the membrane, 2) a pinhole stabilizer and 3) an agent that hinders poisoning. Competition of active sites, the Tamman temperature of Au and the Kirkendall effect [36] could certainly contribute to an explanation of the manifested properties.

The Tamman temperature of $\mathrm{Au}\left(395^{\circ} \mathrm{C}\right)$ is significantly lower than $\mathrm{Pd}\left(641{ }^{\circ} \mathrm{C}\right)$. Therefore, operating at $450{ }^{\circ} \mathrm{C}$, places Au into a state of higher molecular mobility than Pd. In asymmetric membranes, at the $\mathrm{Au}$ Pd boundary, the Kirkendall effect takes place. Gold crosses the Au-Pd boundary and diffuses into the Pd layer; while Pd remains relatively motionless within its limits. This effect allows Au to fill in the voids or defects present in the Pd layer like a patching paste. If the defect is significantly big, Au cannot fix the pinhole. However, its deposition at the walls of the defect seems to stabilize it and prevent further growth. 
The experiments suggested that Au hindered poisoning of the Pd surface. This could be explained by competition for active sites during adsorption. Some of the sites where sulfur adhered were already occupied by Au preventing a strong attachment to the Pd surface. This was supported by the permeance recovery that $\mathrm{Pd} / \mathrm{Au}$ membranes showed when treated under pure $\mathrm{H}_{2}$ at $450^{\circ} \mathrm{C}$ [14].

Platinum also appeared to hinder poisoning in a similar way as Au did, but did not seem to cover the defects of the Pd surface. The Tamman temperature of $\mathrm{Pt}\left(747.4^{\circ} \mathrm{C}\right)$ is higher than $\mathrm{Pd}\left(641^{\circ} \mathrm{C}\right)$. Therefore, for the case of $\mathrm{Pd} / \mathrm{Pt}$ membranes, $\mathrm{Pt}$ was in a state of lower molecular mobility than $\mathrm{Pd}$ and consequently at the Pt-Pd boundary, the Kirkendall effect took place. Pd crossed the Pt-Pd boundary and diffused into the Pt layer; while Pt remained relatively stationary. This effect seemed to generate defects on the Pd layer.

In the case of $\mathrm{Pd} / \mathrm{Au} / \mathrm{Pt}, \mathrm{Au}$ has the highest mobility and can diffuse towards the $\mathrm{Au}-\mathrm{Pd}$ or $\mathrm{Au}-\mathrm{Pt}$. Nevertheless, since the Tamman temperature of Pd is lower than Pt, Au will have a tendency to diffuse towards Pd. That was the reason why the curing effects of Au were notable in the ternary alloy. The diffusion of Pd towards Pt was minimized due to the presence of Au between both metals.

\section{Conclusions}

The effective performance of different Pd and Pd/Alloy composite asymmetric membranes under coalderived syngas at a pilot scale was comparatively assessed. The present research study offers important insights on these membranes in industrial settings by clearly identifying and illustrating their respective strengths and weaknesses which can be condensed as follows:

- Palladium and Pd/Alloy membranes are susceptible to sulfur poisoning at even small quantities mainly resulting in a reduction in $\mathrm{H}_{2}$ permeances.

- The robustness of Pd membranes under industrial settings significantly increases with the existence of an alloy such as Au and/or Pt.

- The use of Pt as a sulfur resistant alloy showed promising preliminary results, but requires further investigation.

- Ternary composite membranes under industrial settings were successfully demonstrated displaying high $\mathrm{H}_{2}$ permeance, good $\mathrm{H}_{2}$ quality and robustness of operation. To the best of our knowledge, this is the first time the results of a performance assessment of Pd/Au/Pt membranes are reported in the pertinent literature.

- It was suspected that $\mathrm{Au}$ is responsible for the protection of the membrane, acting as a patch paste blocking any defects at the surface of the Pd layer.

\section{Acknowledgements}


The authors would like to thank the anonymous reviewers for their helpful comments and suggestions. They are also grateful for the financial support provided by the U.S. Department of Energy through the project "Engineering Design and Advanced $\mathrm{H}_{2} \mathrm{CO}_{2} \mathrm{Pd}$ and $\mathrm{Pd}$ /Alloy Composite Membrane Separations and Process Intensifications" (No. DE-FE0004895).

\section{References}

[1] Koros WJ, Mahajan R. Pushing the limits on possibilities for large scale gas separation: Which strategies? J Membr Sci 2000; 175: 181-196.

[2] Koc R, Kazantzis NK, Ma YH. Membrane technology embedded into IGCC plants with $\mathrm{CO}_{2}$ capture: An economic performance evaluation under uncertainty. Int J Greenh. Gas Contr. 2014; 26: 22-38.

[3] Koc R, Kazantzis NK, Nuttall WJ, Ma YH. An economic evaluation framework for membrane reactors in the presence of uncertainty: The case for process safety investment and risk reduction. J Loss Prev Proc. Ind 2013; 26: 468-477.

[4] Gryaznov VM. Hydrogen permeable palladium membrane catalysts: An aid to the efficient production of ultrapure chemicals and pharmaceuticals. Platinum Metals Rev 1986; 30: 68-72.

[5] Gryaznov VM. Metal containing membranes for the production of ultrapure hydrogen and the recovery of hydrogen isotopes. Separ Purif Method 2000; 29(2): 171-187.

[6] Guazzone F, Catalano J, Mardilovich IP, Kniep J, Pande S, Wu T, Lambrecht RC, Datta S, Kazantzis NK, Ma YH. Gas permeation field tests of composite Pd and Pd-Au membranes in actual coal derived syngas atmosphere. Int J Hydrogen Energy 2012; 37: 14557-14568.

[7] De Falco M, Iaquaniello G, Salladini A. Experimental tests on steam reforming of natural gas in a reformer and membrane modules (RMM) plant. J Membr Sci 2011; 368: 264-274.

[8] Shirasaki Y, Tsuneki T, Ota Y, Yasuda I, Tachibana S, Nakajima H. Development of membrane reformer system for highly efficient hydrogen production from natural gas. Int J Hydrogen Energy 2009; 34, 4482-4487.

[9] Catalano J, Guazzone F, Mardilovich IP, Kazantzis NK, Ma YH. Hydrogen production in a large scale water-gas shift Pd-based catalytic membrane reactor. Ind Eng Chem Res 2013; 52: 1042-1055.

[10] Pomerantz N, Ma YH. Novel method for producing high $\mathrm{H}_{2}$ permeability Pd membranes with a thin layer of the sulfur tolerant Pd/Cu fcc phase. J Membr Sci 2011; 370: 97-108.

[11] Sonwane CG, Wilcox J, Ma YH. Achieving optimum hydrogen permeability in PdAg and PdAu alloys. J Chem Phys 2006; 125: 1-10. 
[12] Ma YH, Chen CH, Catalano J, Guazzone F, Payzant EA. Synthesis, annealing and performances of Pd-Au asymmetric composite membranes for hydrogen purification. Ind Eng Chem Res 2013; 52: 87328744.

[13] Chen $\mathrm{C}$, Ma YH. The effect of $\mathrm{H}_{2} \mathrm{~S}$ on the performance of Pd and Pd/Au composite membrane. J Membr Sci 2010; 362: 535-544.

[14] Guazzone F, Catalano J, Mardilovich IP, Wu T, Lambrecht RC, Datta S, Kniep J, Pande S, Kazantzis

NK, Ma YH. Enhancement of the long-term permeance, selectivity stability, and recoverability of Pd-Au membranes in coal derived syngas atmospheres. Energy Fuels 2013; 27: 4150-4160.

[15] Augustine AS, Mardilovich IP, Kazantzis NK, Ma YH. Durability of PSS-supported Pd-membranes under mixed gas and water-gas shift conditions. J Membr Sci 2012; 415-146: 213-220.

[16] Ma YH, Mardilovich PP, She Y. (2000) Hydrogen gas-extraction module and method fabrication. US Patent No. 6,152,987.

[17] Ma YH, Mardilovich IP, Engwall EE. (2007) Composite gas separation modules having intermediate metal layer. US Patent No. 7,175,694.

[18] Ma YH, Guazzone F. (2010) Method for fabricating a composite has separation module. US Patent No. 7,727,596.

[19] Ma YH, Mardilovich IP, Engwall EE. (2008) Method for fabricating composite gas separation modules. US Patent No. 7,390,536.

[20] Ma YH, Mardilovich IP, Engwall EE. (2007) Method for curing defects in the fabrication of a composite gas separation module. US Patent No. 7,172,644.

[21] Ma YH, Mardilovich IP, Engwall EE. Thin composite palladium and palladium/alloy membranes for hydrogen separation. Ann NYAcad Sci 2003; 984: 346-360.

[22] Ma YH, Mardilovich IP, Engwall EE. (2007) Composite gas separation modules having high Tamman temperature intermediate layers. US Patent No. 7,255,726.

[23] McKinley DL. (1967) Metal alloy for hydrogen separation and purification. US Patent No. $3,350,845$.

[24] Southern company services Inc., Power systems development facility (PSDF) final report, DOE Cooperative Agreement, DE-FC21-90MC25140, April 2009 p. 1-158.

[25] Yun S, Oyama ST. Correlations in palladium membranes for hydrogen separation: A review. J Membr Sci 2011; 375: 28-45.

[26] Guo Y, Hongye Zou, Wu H, Zhou L, Liu H, Zhang X. Preparation of palladium membrane by biomembrane assisted electroless plating for hydrogen separation. Int J Hydrogen Energy 2014; 39: 70697076. 
[27] Zhang K, Gao H, Rui Z, Liu P, Li Y, Lin YS. High-temperature stability of palladium membranes on porous metal supports with different intermediate layers. Ind Eng Chem Res 2009; 48: 1880-1886.

[28] Ryi SK, Lee SW, Oh DK, Seo BS, Park JW, Park JS, Lee DW, Kim SS. Electroless plating of Pd after shielding the bottom of planar porous stainless steel for a highly stable hydrogen selective membrane. J Membr Sci 2014; 467: 93-99.

[29] Berseneva FN, Timofeev NI, Zakharov AB. Alloys of palladium with metals of the platinum group as hydrogen-permeable membrane components at high temperatures of gas separation. Int. J Hydrogen Energy 1993; 19: 15-18.

[30] Noh H, Flanagan TB, Sonoda T, Sakamoto Y. Solubility and thermodynamics of hydrogen in homogeneous f.c.c. Pd-Pt alloys. J Alloys Compd 1995; 228: 164-171.

[31] Vigier F, Jurczakowski R, Lasia A. Determination of hydrogen absorption isotherm and diffusion coefficient in $\mathrm{Pd}_{81} \mathrm{Pt}_{19}$ alloy. J Electroanal Chem 2006; 588: 32-43.

[32] Kajiwara M, Uemiya S, Kojima T. Stability and hydrogen permeation behavior of supported platinum membranes in presence of hydrogen sulfide. Int J Hydrogen Energy 1999; 24: 839-844.

[33] Kim DW, Park YJ, Moon JW, Ryi SK, Park JS. The effect of Cu reflow on the Pd-Cu-Ni ternary alloy membrane fabrication for Infinite hydrogen separation. Thin Solid Films 2008; 516: 3036-3044.

[34] Tarditi AM, Cornaglia LM. Novel $\mathrm{PdAgCu}$ ternary alloy as promising materials for hydrogen separation membranes: Synthesis and characterization. Surf Sci 2011; 605: 62-71.

[35] Coulter KE, Way JD, Gade SK, Chaudhari S, Sholl DS, Semidey-Flecha L. Predicting, fabricating and permeability testing of free-standing ternary palladium-copper-gold membranes for hydrogen separation. J Phys Chem C 2010; 114: 17173-17180.

[36] Kirkendall EO. Diffusion of zinc in alpha brass. Trans AIME 1942; 147: 104-110. 